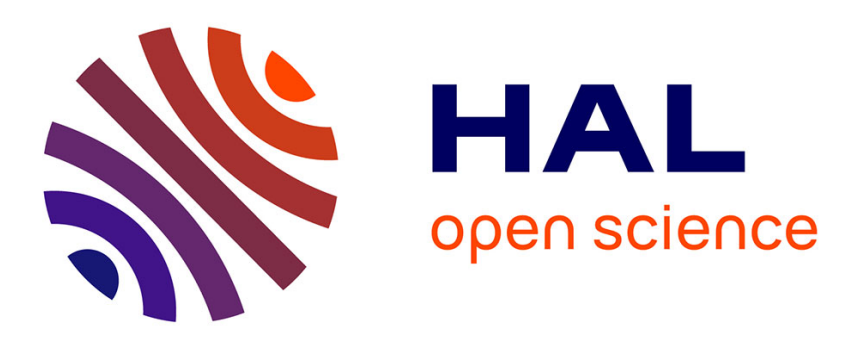

\title{
A novel CLCN5 pathogenic mutation supports Dent disease with normal endosomal acidification
}

\author{
Yohan Bignon, Alexi Alekov, Nadia Frachon, Olivier Lahuna, Carine \\ Jean-Baptiste Doh-Egueli, Georges Deschênes, Rosa Vargas-Poussou, \\ Stéphane Lourdel
}

\section{To cite this version:}

Yohan Bignon, Alexi Alekov, Nadia Frachon, Olivier Lahuna, Carine Jean-Baptiste Doh-Egueli, et al.. A novel CLCN5 pathogenic mutation supports Dent disease with normal endosomal acidification. Human Mutation, 2018, 39 (8), pp.1139-1149. 10.1002/humu.23556 . hal-02452358

\section{HAL Id: hal-02452358 \\ https://hal.sorbonne-universite.fr/hal-02452358}

Submitted on 23 Jan 2020

HAL is a multi-disciplinary open access archive for the deposit and dissemination of scientific research documents, whether they are published or not. The documents may come from teaching and research institutions in France or abroad, or from public or private research centers.
L'archive ouverte pluridisciplinaire HAL, est destinée au dépôt et à la diffusion de documents scientifiques de niveau recherche, publiés ou non, émanant des établissements d'enseignement et de recherche français ou étrangers, des laboratoires publics ou privés. 


\section{A novel CLCN5 pathogenic mutation supports Dent disease with normal endosomal acidification}

\begin{tabular}{|r|l|}
\hline Journal: & Human Mutation \\
\hline Manuscript ID & humu-2018-0037.R1 \\
\hline Wiley - Manuscript type: & Research Article \\
\hline Date Submitted by the Author: & n/a \\
\hline Complete List of Authors: & $\begin{array}{l}\text { Bignon, Yohan; Sorbonne Université, Centre de Recherche des Cordeliers } \\
\text { Alekov, Alexi; Medizinische Hochschule Hannover, Institut für } \\
\text { Neurophysiologie } \\
\text { Frachon, Nadia; Sorbonne Université, Centre de Recherche des Cordeliers } \\
\text { Lahuna, Olivier; Institut Cochin } \\
\text { Jean-Baptiste Doh-Egueli, Carine; CHU de Pointe-à-Pitre, Service de } \\
\text { Pédiatrie Générale } \\
\text { Deschenes, Georges; Assitance Publique - Hôpitaux de Paris, Hôpital } \\
\text { Robert Debré } \\
\text { Vargas-Poussou, Rosa; Assistance Publique-Hôpitaux de Paris, Hôpital } \\
\text { Européen Georges Pompidou } \\
\text { Lourdel, Stéphane; Sorbonne Université, Centre de Recherche des } \\
\text { Cordeliers }\end{array}$ \\
\hline Key Words: & $\begin{array}{l}\text { <i>CLCN5</i>, Endosomal acidification, Gating glutamate, ClC-5, Dent } \\
\text { disease }\end{array}$ \\
\hline \hline
\end{tabular}




\section{A novel CLCN5 pathogenic mutation supports Dent disease with normal endosomal acidification}

Yohan Bignon ${ }^{1}$, Alexi Alekov ${ }^{2}$, Nadia Frachon $^{1}$, Olivier Lahuna ${ }^{3}$, Carine Jean-Baptiste DohEgueli $^{4}$, Georges Deschênes ${ }^{5,6}$, Rosa Vargas-Poussou $^{7,8}$ and Stéphane Lourdel ${ }^{1}$

${ }^{1}$ Sorbonne Université, Université Paris-Descartes, INSERM, CNRS, F-75006, Paris, France ; ${ }^{2}$ Institut für Neurophysiologie, Medizinische Hochschule Hannover, Hannover, Germany ; ${ }^{3}$ INSERM, Institut Cochin, Paris, France ; ${ }^{4} \mathrm{CHU}$ de Pointe-à-Pitre, Service de pédiatrie générale, Pointe-à-Pitre, France ; ${ }^{5}$ Assistance Publique-Hôpitaux de Paris, Hôpital Robert Debré, Service de Néphrologie Pédiatrique, Paris, France ; ${ }^{6}$ Centre de Référence des Maladies Rénales Héréditaires de l'Enfant et de l'Adulte (MARHEA), Paris, France ; ${ }^{7}$ Assistance Publique-Hôpitaux de Paris, Hôpital Européen Georges Pompidou, Département de génétique, Paris, France $;{ }^{8}$ Université Paris-Descartes, Faculté de Médecine, Paris, France.

\section{Corresponding author:}

Dr. Stéphane Lourdel

Centre de Recherche des Cordeliers UMR_S 1138, ERL 8228

15, rue de l'école de médecine, 75006 Paris, France

Phone : +331442751 17 Fax : +33144275119

Email : stephane.lourdel@upmc.fr 


\begin{abstract}
Dent disease in an X-linked recessive renal tubular disorder characterized by lowmolecular-weight proteinuria, hypercalciuria, nephrolithiasis, nephrocalcinosis and progressive renal failure. Inactivating mutations of $C L C N 5$, the gene encoding the $2 \mathrm{Cl}^{-} / \mathrm{H}^{+}$ exchanger ClC-5 have been reported in patients with Dent disease 1. In vivo studies in mice harboring an artificial mutation in the "gating glutamate" of ClC-5 (c.632A $>$ C, p.Glu211Ala) and mathematical modeling suggest that endosomal chloride concentration could be an important parameter in endocytosis, rather than acidification as earlier hypothesized. Here, we described a novel pathogenic mutation affecting the "gating glutamate" of ClC-5 (c.632A $>$ G, p.Glu211Gly) and investigated its molecular consequences. In HEK293T cells, the p.Glu211Gly ClC-5 mutant displayed unaltered N-glycosylation and normal plasma membrane and early endosomes localizations. In X. laevis oocytes and HEK293T cells, we found that contrasting with wild-type $\mathrm{ClC}-5$, the mutation abolished the outward rectification, the sensitivity to extracellular $\mathrm{H}^{+}$and converted $\mathrm{ClC}-5$ into a $\mathrm{Cl}^{-}$channel. Investigation of endosomal acidification in HEK293T cells using the $\mathrm{pH}$-sensitive pHluorin2 probe showed that the luminal $\mathrm{pH}$ of cells expressing a wild-type or p.Glu211Gly ClC-5 was not significantly different. Our study further confirms that impaired acidification of endosomes is not the only parameter leading to defective endocytosis in Dent disease 1.
\end{abstract}

Key words: Dent disease; $C L C N 5$; ClC-5; endosomal acidification; gating glutamate 


\section{INTRODUCTION}

Dent disease is a hereditary $\mathrm{X}$-linked recessive renal proximal tubule disorder characterized by low-molecular-weight-proteinuria (LMWP), and hypercalciuria, inconstantly associated with other signs of Fanconi syndrome. Up to now, there is no specific treatment: Dent disease frequently led to nephrocalcinosis, nephrolithiasis and in many cases chronic renal failure. About two-third of patients display inactivating mutations of the CLCN5 gene (MIM\# 300008) encoding the $2 \mathrm{Cl}^{-} / \mathrm{H}^{+}$exchanger ClC-5 (Dent disease 1, MIM\# 300009), whereas inactivating mutations of the OCRL1 gene (MIM\# 300535) encoding the phosphatidylinositol-4,5-bisphosphate-5-phosphatase have been reported in $\sim 15 \%$ of patients (Dent disease 2, MIM\# 300555) (Hoopes et al., 2005 ; Mansour-Hendili et al., 2015). In the kidney, ClC-5 is abundantly expressed in the early endosomes of proximal tubule cells where it co-localizes with the V-type $\mathrm{H}^{+}$-ATPase and low-molecular-weight proteins after their uptake by endocytosis. Lower levels of expression are also detected at the plasma membrane of these cells, in the thick ascending limb of Henle's loop and in $\alpha$-intercalated cells of the collecting duct (Devuyst, Christie, Courtoy, Beauwens, \& Thakker, 1999 ; Gunther, Luchow, Cluzeaud, Vandewalle, \& Jentsch, 1998 ; Piwon, Gunther, Schwake, Bosl, \& Jentsch, 2000 ; Sakamoto et al., 1999 ; Suzuki et al., 2006). The co-distribution of ClC-5 with the proton pump on early endosomes of proximal tubule cells suggested that it may play a crucial role in receptor-mediated endocytosis by permitting an electrical shunt required for sufficient endosomal acidification by the V-type $\mathrm{H}^{+}$-ATPase (Gunther et al., 1998 ; Piwon et al., 2000). Indeed, disturbed endosomal acidification and endocytosis were observed in ClC-5 knock-out mice (Gunther, Piwon, \& Jentsch, 2003 ; Novarino, Weinert, Rickheit, \& Jentsch, 2010 ; Piwon et al., 2000 ; Wang et al., 2005), in proximal tubule cell lines (Wang et al., 2005) and in immortalized proximal tubule cells from patients with Dent disease (Gorvin et al., 2013). The small amount of $\mathrm{ClC}-5$ detected at the brush border of proximal tubule cells is also 
related to endocytosis, by mediating interactions with several proteins involved in receptormediated endocytosis, such as the multi-ligand receptor megalin and the microtubuledependent motor protein KIF3B (Hryciw, Jenkin, et al., 2012 ; Hryciw, Kruger, et al., 2012 ; Hryciw, Ekberg, Pollock, \& Poronnik, 2006 ; Reed et al., 2010 ; Wang et al., 2005).

$\mathrm{ClC} 2 \mathrm{Cl}^{-} / \mathrm{H}^{+}$exchangers carry a critical glutamate residue that plays a key role in the coupling of $\mathrm{H}^{+}$to $\mathrm{Cl}^{-}$flux (Dutzler, Campbell, Cadene, Chait, \& MacKinnon, 2002 ; Dutzler, Campbell, \& MacKinnon, 2003; Feng, Campbell, Hsiung, \& MacKinnon, 2010). An artificial mutation of this "gating glutamate" to alanine in ClC-5 (c.632A $>$ C, p.Glu211Ala) and in other $\mathrm{ClC}$ abolished $\mathrm{H}^{+}$flux and allowed the observation of pure $\mathrm{Cl}^{-}$conductance (Accardi \& Miller, 2004 ; Feng et al., 2010 ; Matsuda, Filali, Collins, Volk, \& Lamb, 2010 ; Neagoe, Stauber, Fidzinski, Bergsdorf, \& Jentsch, 2010 ; Picollo \& Pusch, 2005 ; Scheel, Zdebik, Lourdel, \& Jentsch, 2005). Interestingly, mice carrying the p.Glu211Ala (E211A) artificial mutation that converts $\mathrm{ClC}-5$ to a pure $\mathrm{Cl}^{-}$channel displayed the same renal phenotype as $\mathrm{ClC}-5$ knock-out, including LMWP proteinuria, despite normal endosomal acidification (Novarino et al., 2010). Model calculations indicate that such a $\mathrm{Cl}^{-}$conductance may permit sufficient acidification, but leads to a reduced $\mathrm{Cl}^{-}$endosomal accumulation (Weinert et al., 2010).

It was also found in heterologous expression systems and in immortalized proximal tubule cells from patients that some CLCN5 mutations result in unaltered endosomal $\mathrm{pH}$ (Gorvin et al., 2013 ; Smith, Reed, Loh, Thakker, \& Lippiat, 2009). Altogether, these results suggest that endosomal chloride accumulation during $\mathrm{ClC}-5$ transport in proximal tubule cells may be critical in endocytosis, rather than acidification as first hypothesized. They also indicate that the role of $\mathrm{ClC}-5$ in the physiopathology of the disease is more complex than previously assumed. 
To date, at least 234 CLCN5 inactivating mutations have been identified in patients with Dent disease type 1 (Mansour-Hendili et al., 2015). Functional investigations using $X$. laevis oocytes and mammalian cells allowed the division of CLCN5 missense mutations into different classes (D’Antonio et al., 2013 ; Grand et al., 2009, 2011 ; Lourdel et al., 2012 ; Ludwig et al., 2005 ; Smith et al., 2009): the most frequent class includes mutations leading to a defect in protein folding and processing resulting in endoplasmic reticulum retention of the mutant protein for further degradation by the proteasome. Another class of mutations alters electrical activity but not the trafficking of the mutant protein to the plasma membrane and the early endosomes. Some mutations cause a delay in protein processing and reduce the stability of the mature form. Finally, three mutations have been described which surprisingly do not affect endosomal acidification (Gorvin et al., 2013 ; Smith et al., 2009).

In this study, we report clinical data describing the phenotype of a Dent disease 1 young patient carrying a novel pathogenic CLCN5 missense mutation c.632A $>\mathrm{G}$, pGlu211Gly (E211G) affecting the critical "gating glutamate" of C1C-5. We have investigated the molecular consequences of such a mutation on ClC-5 electrophysiological properties and on endosomal acidification, using X. laevis oocytes and HEK293T cells. Our results support the existence of ClC-5 mutations that do not lead to defective endosomal acidification despite their association with all classical clinical features of Dent disease. Such type of mutations further highlights the potential importance of endosomal chloride concentration for proximal tubule cells endocytosis. 


\section{MATERIAL AND METHODS}

\section{DNA sequence analysis of the $C L C N 5$ gene}

Peripheral blood samples were obtained from the patient and genomic DNA was extracted by standard methods. The coding exons (2 to 12) and intron-exon junctions were amplified with $C L C N 5$-specific primers described elsewhere using PCR amplification (Lloyd et al., 1997). We carried out direct sequencing using the dioxy chain termination method on an automated Division 373A Stretch DNA capillary sequencer (Perkin Elmer/Applied Biosystems, CA, USA), and evaluated sequences with Sequencher software (Gene Codes, MI, USA). For in silico analysis we used Alamut V.2.10 software (Interactive Biosoftware, Rouen, France; http://www.interactivebiosoftware.com), which includes splice site predictions algorithms (SpliceSiteFinder, MaxEntScan NNSPLICE, GeneSplicer and HumanSplicingFinder). The variant reported in this article has been submitted to LOVD v.3 database at www.lovd.nl/CLCN5.

The patient belongs to a study that was approved by the "Comité de Protection des Personnes, Paris-Île de France XI (Ref. 09069)” and informed consent for genetic studies was obtained from his parents.

\section{Molecular Biology}

The human coding sequence of wild-type ClC-5 (GenBank NM_000084.4) was subcloned either into the pTLN vector (a generous gift of Dr. Thomas J. Jentsch, MDC/FMP, Berlin, Germany) for expression in $X$. laevis oocytes, or into the peGFP and pRcCMV vectors for expression in HEK293T. In the peGFP vector, the coding sequence for GFP has been substituted for those of ClC-5. The HA epitope (YPYDVPDYA) is introduced between amino acids 107 and 108 of ClC-5 in pTLN and pEGFP vectors, or between amino acids 392 and 393 in the pRcCMV vector containing the fluorescent mCherry fused to the C-terminus 
of ClC-5, as previously described (Grand et al., 2011 ; Grieschat \& Alekov, 2014). The ClC-5 c.632A $>\mathrm{G}$ mutation $(\mathrm{E} 211 \mathrm{G})$ was introduced in those vectors by site-directed mutagenesis using the Quickchange site-directed mutagenesis kit (Stratagene, CA, USA). All constructs were fully sequenced before use. The synapto-pHluorin2 construct was kindly provided by Dr. Raul Guzman (FZ Jülich, Jülich, Germany). For its creation, we used the original vesicular pH reporter synapto-pHluorin kindly provided by Dr. Miesenböck (Miesenböck, De Angelis, \& Rothman, 1998). In our construct, we replaced the fluorescent GFP-based pHluorin with the newer and brighter pHluorin2 (Mahon, 2011) obtained as a gift from Dr. Mahon. Finally, the synapto-pHluorin2 sequence was subcloned into the p156rrL vector using standard PCR procedures.

\section{Expression in $X$. laevis oocytes}

Capped cRNA were synthetized in vitro from pTLN expression vectors using the SP6 mMessage mMachine Kit (Ambion, TX, USA). Defolliculated X. laevis oocytes were injected with $50 \mathrm{nl}$ of RNAse free-water containing $20 \mathrm{ng}$ of the different cRNAs and were then kept at $17^{\circ} \mathrm{C}$ in modified Barth's solution containing (in $\mathrm{mM}$ ): $88 \mathrm{NaCl}, 1 \mathrm{KCl}, 0.41$ $\mathrm{CaCl}_{2}, 0.33 \mathrm{Ca}\left(\mathrm{NO}_{3}\right)_{2}, 0.82 \mathrm{MgSO}_{4}, 10 \mathrm{HEPES}, \mathrm{pH} 7.4$, and supplemented with $10 \mathrm{U} / \mathrm{ml}$ of penicillin and $10 \mu \mathrm{g} / \mathrm{ml}$ streptomycin (ThermoFischer, MA, USA).

\section{Surface labeling of oocytes}

Experiments were performed as previously described (Grand et al., 2011). Briefly, a rat monoclonal anti-HA antibody (3F10, Roche Diagnostics, France) was used as primary antibody and a peroxidase-conjugated goat anti-rat antibody (Jackson ImmunoResearch, PA, USA) as secondary antibody. Chemiluminescence was quantified using a Turner TD-20/20 
luminometer (Turner Designs, CA, USA) by placing individual oocytes in $50 \mu 1$ of SuperSignal Elisa Femto Maximum Sensitivity Substrate Solution (Pierce, IL, USA).

\section{Voltage-clamp in $X$. laevis oocytes}

Two days after injection, two-electrode voltage-clamp experiments were performed at room temperature using a TEV-200A amplifier (Dagan, MN, USA) and PClamp 10 software (Axon Instruments, CA, USA). Currents were recorded in ND96 solution containing (in $\mathrm{mM}): 96 \mathrm{NaCl}, 2 \mathrm{KCl}, 1.5 \mathrm{CaCl}_{2}, 1 \mathrm{MgCl}_{2}, 5$ HEPES, pH 7.4. For $\mathrm{pH}$ 5.5, 6.5 and 7.0, $5 \mathrm{mM}$ HEPES was replaced by $5 \mathrm{mM}$ MES. For pH 8.5, $5 \mathrm{mM}$ HEPES was replaced by $5 \mathrm{mM}$ Trizma Base. Currents were recorded in response to a voltage protocol consisting of $20 \mathrm{mV}$ steps from $-100 \mathrm{mV}$ to $+100 \mathrm{mV}$ during $800 \mathrm{~ms}$ from a holding potential of $-30 \mathrm{mV}$.

\section{Whole-cell recordings}

An EPC-10 amplifier controlled by the PATCHMASTER software package (both from HEKA Electronics), was used to perform whole-cell patch-clamp (Hamill, Marty, Neher, Sakmann, \& Sigworth, 1981). Currents were recorded after filtering at $3 \mathrm{kHz}$ and digitalization at $100 \mathrm{kHz}$ sampling rate. To reduce series resistance voltage errors, capacitance cancelation and series resistance compensation were applied. Recordings for which the uncompensated error exceeded $5 \mathrm{mV}$ were discarded. Patch pipettes with resistances between 1.2-1.8 $\mathrm{M} \Omega$ were filled with a patch pipette solution containing (in $\mathrm{mM}$ ): $110 \mathrm{NaCl}, 5 \mathrm{MgCl}_{2}, 5$ EGTA and 10 HEPES ( $\mathrm{pH}$ 7.4). The standard extracellular solution contained (in $\mathrm{mM}$ ) $145 \mathrm{NaCl}, 4 \mathrm{KCl}, 2 \mathrm{CaCl}_{2}, 1 \mathrm{MgCl}_{2}$, and $15 \operatorname{HEPES}(\mathrm{pH} 7.4$ ). 


\section{Cell culture and transfection}

HEK293T cells used for biochemistry were grown at $37^{\circ} \mathrm{C}$ and $5 \% \mathrm{CO}_{2}$, in Dulbecco's Modified Eagle's Medium (Gibco, CA, USA) supplemented with $10 \%$ fetal bovine serum (Eurobio, France) and a penicillin/streptomycin mix (ThermoFischer, MA, USA) to a final concentration of $100 \mathrm{U} / \mathrm{ml}$ and $100 \mathrm{mg} / \mathrm{ml}$, respectively. The cells were transiently transfected with 1 ug of pEGFP plasmid using X-tremeGENE 9 DNA transfection Reagent (Sigma Aldrich, MO, USA) according to the manufacturer's instructions.

HEK 293 T cells used for electrophysiology and vesicular $\mathrm{pH}$ measurements were cultured in DMEM (Gibco, CA, USA) supplemented with 10\% FBS (Biochrom AG, Germany), 2 mM L-glutamine and 50 units/ml penicillin/streptomycin (ThermoFischer, MA, USA). Cells were transfected using standard calcium phosphate precipitation method (Graham \& van der Eb, 1973) using $10 \mu \mathrm{g}$ of pRcCMV-ClC-5 DNA alone or in combination with $5 \mu$ g synapto-pHluorin2 plasmid.

\section{Surface biotinylation of HEK293T cells}

Forty-eight hours after transfection, cells were placed 30 minutes on ice and rinsed three times with a cold PBS solution $\mathrm{pH} 8.0$ supplemented with $100 \mathrm{mM} \mathrm{CaCl} 2$ and $1 \mathrm{mM}$ $\mathrm{MgCl}_{2}$ (PBS++). Cells were then incubated at $4^{\circ} \mathrm{C}$ for 1 hour with $1.5 \mathrm{mg} / \mathrm{ml}$ biotin in cold PBS $++\mathrm{pH}$ 8.0. After 1 hour at $4^{\circ} \mathrm{C}$ in a quenching solution, cells were washed three times in ice cold PBS++. When surface biotinylation was followed by western blotting analysis, the biotin and the quenching solutions contained the reducible Sulfo-NHS-SS-biotin (Pierce, IL, USA) and $0.1 \%$ BSA in PBS++, respectively. When surface biotinylation was followed by immunocytochemistry, the biotin and the quenching solutions contained the non-reducible Sulfo-NHS-LC-biotin (Pierce, IL, USA) and $100 \mathrm{mM}$ Glycine in PBS++ pH 8.0, respectively. 


\section{Total and surface protein isolation}

Forty-eight hours after transfection, cells were incubated and scratched at $4{ }^{\circ} \mathrm{C}$ in a lysis solution containing $150 \mathrm{mM} \mathrm{NaCl}, 50 \mathrm{mM}$ Tris-HCl, $1 \mathrm{mM}$ EDTA, $1 \%$ NP-40, $0.2 \%$ SDS pH 7.4 and a Complete EDTA Free protease inhibitor mix (Roche Diagnostics, France). Extracts turned 30 minutes at $4{ }^{\circ} \mathrm{C}$ on a wheel to solubilize proteins and were then centrifuged at $5000 \mathrm{~g}$ during 10 minutes. Protein concentration in the resulting supernatant was quantified using the BCA Protein Assay quantification kit (Pierce, IL, USA). For protein extraction from surface-biotinylated HEK293T cells, lysis solution contained $50 \mathrm{mM}$ Tris-HCl, $2 \mathrm{mM}$ EDTA, $2 \mathrm{mM}$ EGTA, $30 \mathrm{mM} \mathrm{NaF}, 30 \mathrm{mM}$ NaPPi, 1\% Triton and 0.1\% SDS and a Complete EDTA Free protease inhibitor mix (Roche Diagnostics, France). Protein extracts were subjected to centrifugation during 3 minutes at $15000 \mathrm{~g}$.

Isolation of biotinylated proteins was performed using $100 \mu \mathrm{g}$ of fresh total protein extracts from surface-biotinylated HEK293T cells and NeutrAvidin-agarose beads (Pierce, IL, USA). For each reaction, washed and dried beads from $110 \mu 1$ of the provided $50 \%$ slurry were diluted into $500 \mu \mathrm{l}$ of a TLB solution containing (in $\mathrm{mM}$ ): 50 Tris $\mathrm{HCl}, 100 \mathrm{NaCl}, 5$ EDTA and a Complete EDTA Free protease inhibitor mix (Roche Diagnostics, France) and mixed with biotinylated protein extract. After overnight agitation at $4^{\circ} \mathrm{C}$, beads were centrifuged 2 minutes at $2500 \mathrm{~g}$ and were washed with TLB solution four times, to remove non-biotinylated proteins in the supernatant. Finally, dried beads were incubated 10 minutes at $95^{\circ} \mathrm{C}$ with $50 \mu \mathrm{l}$ of denaturing buffer, vortexed, centrifuged 2 minutes at $2500 \mathrm{~g}$ and $35 \mathrm{ul}$ from supernatant of denatured surface proteins were loaded in a polyacrylamide gel well. 


\section{Western blot analysis}

Twenty micrograms of total proteins or total surface protein extracts were separated on an $10 \%$ SDS-PAGE gel and transferred to nitrocellulose membranes. The blocking solution contained $5 \%$ of non-fat milk proteins added in the washing buffer TBS $+0.2 \%$ NP-40. Primary antibodies were monoclonal 3F10 rat anti-HA (Roche Diagnostics, France; 1:1500) and monoclonal A2228 mouse anti- $\beta$-Actine (Sigma Aldrich, MO, USA; 1:20000). Peroxidase-conjugated secondary antibodies were goat anti-rat antibody (Jackson ImmunoResearch, PA, USA; 1:10000) and sc-2005 goat anti-mouse (Santa Cruz; 1:10000). Antibodies were diluted in TBS blocking solution and incubated with membrane under constant agitation, overnight at $4^{\circ} \mathrm{C}$ or 1 hour at room temperature. Indirect protein detection was performed by chemiluminescence using the Pierce ${ }^{\mathrm{TM}}$ ECL Western Blotting Substrate (ThermoFischer, MA, USA). The protein signal was quantified using the ImageJ freeware (NIH, Bethesda, USA) and normalized on the $\beta$-actin signal (used as loading control).

\section{Immunocytochemistry and confocal Imaging}

Forty-eight hours after transfection on poly-L-lysine coated coverslips, HEK293T cells were washed with PBS, fixed in $4 \%$ paraformaldehyde and permeabilized with $0.1 \%$ Triton. Nonspecific binding sites were blocked with a $10 \%$ goat serum solution, in which antibodies were then incubated with cells during 1 hour at room temperature. Primary antibodies were H3663 mouse anti-HA (Sigma Aldrich, MO, USA; 1:200), Ab2900 rabbit anti-EEA1 (Abcam, Cambridge, UK; 1:200) and secondary antibodies were 115-095 FITCconjugated goat anti-mouse (Jackson ImmunoResearch, PA, USA; 1:250), A21428 AlexaFluor ${ }^{\mathrm{m}} 555$-conjugated goat anti-rabbit (ThermoFischer, MA, USA); 1:250). In the course of surface biotin labelling, cells were biotinylated as described above, extra biotin was removed and cells were washed prior to chemical fixation with PFA. At the end of 
immunocytochemistry, Cy5-conjugated Streptavidin (ThermoFischer, MA, USA; 1:200) was incubated with cells in the same time than A11059 rabbit anti-mouse AlexaFluor ${ }^{\mathrm{TM}} 488$ conjugated antibody (Life Technologies; 1:200). Labeled cells were analyzed with a Zeiss LSM 710 confocal laser-scanning microscope.

\section{Fluorescence measurements of intracellular pH}

Measurements of intracellular $\mathrm{pH}$ in the whole-cell patch clamp configuration were described in detail elsewhere (Alekov \& Fahlke, 2009). In brief, cells were loaded with 37.5 $\mu \mathrm{M} \quad$ 2',7'-bis(2-carboxyethyl)-5(and 6)-carboxyfluorescein (BCECF, Wako Chemicals) through the patch pipette. For these experiments, the proton buffering capacity of the intracellular patch-clamp solution (see above) was lowered by reducing its HEPES content to $0.25 \mathrm{mM}$. BCECF fluorescence was detected through an UPlanSApo 60x/NA1.35 oil immersion objective mounted on an Olympus IX-71 microscope. Sequential excitation at 490 and $440 \mathrm{~nm}$ was applied using a Polychrome $\mathrm{V}$ monochromator and the fluorescence was detected at $530 \mathrm{~nm}$ with a photodiode (both from Till Photonics). The resultant fluorescence ratio F490/F440 was converted to absolute $\mathrm{pH}$ by using a calibration curve, previously obtained ex situ (see description in (Alekov \& Fahlke, 2009)).

\section{Vesicular pH measurement and confocal Imaging}

Ratiometric measurements of vesicular $\mathrm{pH}$ were performed as described previously (Alekov, 2015). In brief, WT or mutant ClC-5 were co-expressed with synapto-pHluorin2 in HEK293T cells. The fluorescence of an mCherry tag covalently linked to the C-terminus of the $\mathrm{ClC}$ transporter was used to identify vesicles containing $\mathrm{ClC}-5$. Subsequently, the $\mathrm{pH}$ in these vesicles was determined ratiometrically using a dual wavelength excitation of the fluorescent pHluorin2 construct containing a covalently linked fused synapto-pHlyuorin2. 
Images were acquired 24-48 $\mathrm{h}$ after transfection on a Carl-Zeiss LSM 780 inverted microscope using a 40x water immersion objective. The pHluorin2 and mCherry fluorophores were excited at 405/488 and $561 \mathrm{~nm}$ and emission was detected at 500-550 and 560-650 nm, respectively. Live cell imaging was performed in PBS containing $\mathrm{Ca}^{2+}$ and $\mathrm{Mg}^{2+}$ (Gibco, CA, USA) at room temperature $\left(22-24^{\circ} \mathrm{C}\right)$. A calibration curve was constructed to convert the ratio of the pHluorin2 fluorescence as excited with 405 and $488 \mathrm{nM}$ in absolute pH. To this end, cells were bathed in potassium-based solutions with different $\mathrm{pHs}$ supplemented with $10 \mu \mathrm{M}$ nigericin. The analysis of the calibration data was performed using Carl Zeiss Zen lite 2011 (Blue edition) software. Particle detection was performed using the MatLab (MathWorks) adaptation by Blair and Dufresne of the original Crocker and Grier algorithm (Crocker \& Grier, 1996). The code was incorporated into house-written MatLab script (Alekov, 2015) that carried out automatic background subtraction, segmentation ratiometric analyses of the identified vesicular regions. Images were assembled for figure visualization with IMAGEJ (Rasband, n.d.).

\section{Statistics}

Results are given as means \pm SEM for the indicated $n$ number of experiments. A significance difference between means was considered when a $\mathrm{P}$ value $<0.05$ was obtained after running a bilateral Student's $t$ test. 


\section{RESULTS \\ E211G mutation causes progressive Dent disease type 1 in a young patient}

The patient is the first son of unrelated parents. He was born at term of 39 weeks after an uneventful pregnancy, with body weight of 3,070 $\mathrm{g}$ and height of $48 \mathrm{~cm}$. At 4 months of age, failure to thrive was observed. At one year and a half, he was hospitalized for severe dehydration ( $>10 \%$ BW) with hyponatremia, hypokalemia, hypouricemia and hypophosphatemia (Table 1). Renal Ultrasound showed no nephrocalcinosis. He received intravenous rehydration and ambulatory treatment with salt and phosphate supplementation. Four months later, an hospitalization in a tertiary care center showed failure to thrive, similar electrolyte abnormalities and the urinary analysis suggested a diagnosis of Fanconi syndrome due to the association of salt loosing with secondary hyperaldosteronism, renal hypokalemia and hypouricemia, aminoaciduria, hypercalciuria, low molecular weight proteinuria (LMWP) and stage 2 CKD: eGFR (estimated glomerular filtration rate) was $78 \mathrm{ml} / \mathrm{mn} / 1.73 \mathrm{~m}^{2}$. X-ray examination show a bone age concordant with chronological age and no rickets.

The diagnosis of cystinosis was excluded (intraleucocytary cystine at $0.23 \mathrm{nmol} / \mathrm{mg}$, no cysteine crystals in retina or cornea and normal sensitivity to light) and diagnosis of Dent disease was considered. Direct sequencing of CLCN5 gene from peripheral genomic DNA reveals a c.632A $>$ G, p.Glu211Gly (E211G) variation in the coding exon 6 . This missense change is predicted in silico as pathogenic and does not induced modification in the splice site scores. Family screening showed no LMWP and mild hypercalciuria in his mother (Table 1). Unfortunately, the compliance to treatment and to medical follow-up of this patient and his family is poor and in the last years he has only consulted to the emergency services twice during acute episodes associated with dehydration. At last follow-up, his eGFR calculated by Schwartz formula was $55 \mathrm{ml} / \mathrm{min} / 1.73 \mathrm{~m}^{2}$. 


\section{E211G mutation alters currents and sensitivity to external pH}

To characterize functionally the ClC-5 E211G mutant, we first injected wild-type (WT) and mutant human ClC-5 cRNA into X. laevis oocytes (Figure 1). Two electrode voltage-clamp recordings revealed typical strongly outwardly rectifying currents for the oocytes expressing WT ClC-5 (Friedrich, Breiderhoff, \& Jentsch, 1999 ; Grand et al., 2009, 2011 ; Picollo \& Pusch, 2005; Scheel et al., 2005; Steinmeyer, Schwappach, Bens, Vandewalle, \& Jentsch, 1995). In contrast, we observed that the E211G mutant displayed a nearly linear current/voltage relationship as already described for the artificial E211A and the recently described pathogenic c.631G $>$ C, p.Glu211Gln (E211Q) mutants (Friedrich et al., 1999 ; Picollo \& Pusch, 2005 ; Satoh et al., 2016 ; Scheel et al., 2005) (Figure 1A-B). The currents recorded with the E211G mutant were significantly reduced by $38 \%$ in comparison to those of WT ClC-5 at positive membrane voltages. To further elucidate the mechanisms leading to reduced electrical activity, we investigated the plasma membrane targeting of the ClC-5 mutant using a chemiluminescence assay by taking advantage of the extracellular HA epitope on ClC-5. We found that the normalized luminescence responses did not significantly differ between WT ClC-5 and the E211G mutant (Figure 1C). Thus, the reduced current amplitude of the mutant cannot be attributed to reduced cell surface expression. Furthermore, as previously reported (Friedrich et al., 1999 ; Picollo \& Pusch, 2005 ; Scheel et al., 2005), currents from WT ClC-5 were reduced by an extracellular acidification. Conversely, currents from the E211G mutant did not responded to extracellular pH changes (Figure 1D).

\section{E211G mutation has no effect on plasma membrane and early endosomes localization}

To further document the subcellular localization of the mutant $\mathrm{ClC}-5$, we performed confocal microscopy imaging in transiently-transfected HEK293T cells, a mammalian cell line that is appropriate for such analysis (Alekov, 2015 ; Grand et al., 2009, 2011 ; Satoh et 
al., 2016). As previously reported (Alekov, 2015 ; Grand et al., 2009, 2011 ; Smith et al., 2009 ; Tang et al., 2016), Figure 2 shows that WT ClC-5 co-localized with biotinylated cellsurface proteins, and with the early endosomes marker EEA1. Similarly, the C1C-5 E211G mutant co-localized with biotinylated cell-surface proteins and EEA1 (Figure 2). We also carried out surface biotinylation experiments using transiently-transfected HEK293T cells to further explore the plasma membrane expression of the mutant ClC-5. No significant differences could be detected in the surface fraction containing WT ClC-5 and the E211G mutant (Figure 3A). Overall, these data indicate that the E211G mutation lead to normal plasma membrane and early endosomes expression of ClC-5.

\section{E211G mutation does not result in altered protein expression and maturation}

We next examined the impact of the E211G mutation on ClC-5 protein expression. Total cell lysates isolated from HEK293T cells transfected transiently with WT or mutant ClC-5 were subjected to a western blot analysis (Figure 3B). In agreement with previous reports (Grand et al., 2009, 2011), WT ClC-5 expression produced two main immunoreactive signals at $\sim 75$ and $\sim 80-90 \mathrm{kDa}$. The lower band corresponds to the core-glycosylated form of $\mathrm{ClC}-5$ that is retained in the endoplasmic reticulum, whereas the upper band corresponds to the complex-glycosylated form of $\mathrm{ClC}-5$ that is present at the plasma membrane. Here, when an equivalent amount of proteins was loaded in each lane, we observed no quantitative or qualitative signal difference between WT ClC-5 and the E211G mutant. Thus, the E211G does not change the stability or N-glycosylation of ClC-5. 


\section{E211G mutation uncouples $\mathrm{Cl}^{-} / \mathrm{H}^{+}$exchange}

Overall, our results demonstrate that the E211G mutation does not alter the subcellular localization and protein expression of $\mathrm{ClC}-5$, but leads to an alteration of its function. Interestingly, the insensitivity of the E211G mutant to extracellular acidification reported in $X$. laevis oocytes (Figure 1D) was similar to data obtained for the E211A and E211Q mutants and thus suggests that the mutation may convert $\mathrm{ClC}-5$ into a pure chloride conductance by eliminating the coupling of the $\mathrm{H}^{+}$currents to the $\mathrm{Cl}^{-}$flux (Picollo \& Pusch, 2005 ; Satoh et al., 2016; Scheel et al., 2005). Therefore, we then investigated proton transport of the mutant in HEK293T transfected cells. For this purpose, we measured the variations of the intracellular $\mathrm{pH}$ of cells expressing WT or E211G ClC-5 upon membrane depolarization by using the ratiometric $\mathrm{pH}$-sensitive fluorescent indicator BCECF. The plasma membrane was patch-clamped and subjected to different voltages using the wholecell configuration. Similar to recordings in $X$. laevis oocytes, currents obtained with the E211G mutant exhibited abolished outward rectification. Currents from the previously reported ClC-5 E211Q mutant (Satoh et al., 2016) were significantly lower compared to those of the E211G mutant (Figure 4A-B). In contrast to data recorded with WT ClC-5, exposure of transfected cells with the E211G mutant to positive membrane voltages did not lead to significant voltage-dependent intracellular $\mathrm{pH}$ changes (Figure 4C). The voltage-dependence of the rate of the intracellular $\mathrm{pH}$ change of cells expressing WT ClC-5 correlated well with the voltage-dependence of the currents obtained with WT ClC-5 (Figure 4D). Such relationship could not be obtained with the ClC-5 E211G mutant despite significant currents at positive and negative membrane voltages in HEK293T cells. These results therefore demonstrate that the $\mathrm{ClC}-5 \mathrm{E} 211 \mathrm{G}$ mutant behaves as a pure $\mathrm{Cl}^{-}$channel. 


\section{E211G mutation results in unaltered endosomal acidification}

The localization of ClC-5 in early endosomes suggests an involvement in proximal tubule endocytosis by permitting intraluminal acidification, in agreement with the LMWP that is observed in patients with Dent disease (Devuyst \& Luciani, 2015). Thus, we next investigated the effect of the E211G mutation on endosomal acidification in transfected HEK293T cells using the pH-sensitive GFP variant pHluorin2 fused to the C-terminus of the vesicular protein synaptobrevin (Alekov, 2015). As expected from a previous report (Alekov 2015), ClC-5 and synapto-pHluorin2 showed endosomal co-localization (Figure 5A). The analysis of $\mathrm{ClC}-5$-containing endosomes (Figure 5B) showed that the E211G mutation lead to endosomal acidification ( $\mathrm{pH} 6.39 \pm 0.05, n=41$ ) that was not significantly different to those elicited by WT ClC-5 (pH $6.24 \pm 0.06, n=30$ ) (Figure 5C). Endosomal pH was, however, significantly different between mock cells and cells expressing WT ClC-5 or the E211G mutant. Thus, E211G ClC-5 is still able to mediate proper early endosomal acidification. 


\section{DISCUSSION}

Here, we report a novel ClC-5 mutation (E211G) found in a young patient with Dent disease 1. Because the mutation affects the critical "gating glutamate" that is responsible for coupling the $\mathrm{Cl}^{-}$flux to the $\mathrm{H}^{+}$counter-transport in $\mathrm{ClC}-5$, we investigated in vitro its functional consequences.

Using voltage-clamp recordings in $X$. laevis oocytes, we showed that the outward rectification and the sensitivity to extracellular $\mathrm{H}^{+}$were abolished in the E211G mutant in contrast to WT ClC-5. Such alterations in ion conduction have already been observed for the artificial E211A and the pathogenic E211Q mutations. These amino acid substitutions directly affect the "gating glutamate" and lead $\mathrm{ClC}-5$ to function as a $\mathrm{Cl}^{-}$channel (Picollo \& Pusch, 2005 ; Satoh et al., 2016 ; Scheel et al., 2005). Consistent with these observations, we have also demonstrated that this mutant $\mathrm{ClC}-5$ behaves as a pure $\mathrm{Cl}^{-}$channel. Furthermore, the mutant displayed similar protein processing, plasma membrane and early endosomes distribution than WT ClC-5. Unaltered subcellular localization has already been described for the E211Q mutant, except that higher protein expression levels were reported for this mutant (Satoh et al., 2016).

It is postulated that defect in endosomal acidification consecutive to the loss-offunction of $\mathrm{ClC}-5$ is of crucial importance for proper proximal tubule endocytosis (Devuyst \& Luciani, 2015 ; Jentsch, 2015). Remarkably, using the ratiometric pH-sensitive GFP variant pHluorin2 in HEK293T cells, we demonstrated that the E211G mutation is not associated with defective endosomal acidification, given that the mean intraluminal $\mathrm{pH}$ did not significantly differ between cells expressing WT or the mutant ClC-5. This result is in sharp contrast with previous findings reported for endosomal acidification in HEK293T cells expressing the E211Q mutant. Despite unaltered early endosomes targeting of the mutant protein, the vesicular $\mathrm{pH}$ of these cells was significantly higher compared to cells expressing 
WT ClC-5 (Satoh et al., 2016). Changes in current amplitudes of the mutant proteins could explain this difference. Indeed, E211G and E211A produce currents amplitude moderately reduced compared to that of WT ClC-5 (Picollo \& Pusch, 2005). Conversely, our recordings in HEK293T cells demonstrated that the E211Q mutation results in dramatically lower currents compared to those of the E211G mutant. Thus, the change of the acidic amino acid E for a polar uncharged amino acid as Q, induces lower currents than the change for a hydrophobic amino acid as $\mathrm{G}$ or $\mathrm{A}$. In addition, $\mathrm{Q}$ and $\mathrm{E}$ have larger side chain compared with other studied amino acids and particularly with G and A, which are the two smallest amino acids. It seems, therefore, that not only the charge of the amino acid side chain at position 211 but also its size are important for the biophysical properties of ClC-5. Furthermore, in vitro E211Q and E211A are associated with defective endosomal acidification while E211G exhibit normal acidification (Satoh et al., 2016 ; Smith \& Lippiat, 2010). ClC-5 mutants with large electrically neutral side chain at position 211 (such as E211Q) might, therefore, exhibit insufficient electrical activity and reduce thereby the electrical shunt required by the V-type $\mathrm{H}^{+}$-ATPase. This would inhibit further $\mathrm{H}^{+}$pumping by the V-type $\mathrm{H}^{+}$-ATPase, and the vesicular $\mathrm{pH}$ would be quite distant from its physiological value. Interestingly, our findings are similar with data previously generated by Jentsch's group using the E211A mouse model (Novarino et al., 2010). Despite normal acidification of isolated early endosomes from the renal cortex, these mice displayed impaired proximal tubule endocytosis that was comparable to that observed in ClC-5 knock-out mice. Such phenotype was ascribed to reduced $\mathrm{Cl}^{-}$concentration in endosomes resulting during acidification from the activity of a $\mathrm{Cl}^{-}$channel instead of a $2 \mathrm{Cl}^{-} / \mathrm{H}^{+}$exchanger. This would in turn impair the endosomal/lysosomal pathway of the proximal tubule (Novarino et al., 2010 ; Weinert et al., 2010). 
In Dent' diseases 1, no correlation between type of mutation and phenotype has been described (Mansour-Hendili et al., 2015). Patient harboring E211Q mutation has high LMWP (urinary $\beta-2$ microglobuline $37.5 \mathrm{mg} / \mathrm{L}$ ), hypercalciuria, nephrocalcinosis and normal renal function at 7.4 years old. Our patient harboring E211G mutation also has high LMWP (urinary $\alpha-1$ microglobuline $196 \mathrm{mg} / \mathrm{L}$ ), hypercalciuria without nephrocalcinosis but developed CKD at 5 years old.

Our data demonstrate that LMWP proteinuria observed in the patient harboring the E211G mutation cannot be explained by alterations in endocytosis due to defective endosomal acidification, but rather strongly suggest an involvement of intraluminal $\mathrm{Cl}^{-}$in this phenomenon (Smith \& Lippiat, 2010). Interestingly, the pivotal role of ClC-5 in controlling vesicular $\mathrm{Cl}^{-}$concentration for proper proximal tubule endocytosis is further highlighted by other functional studies using different cell lines. Indeed, three other ClC-5 pathogenic mutations c.170G $>$ T, p.Gly57Val (G57V), c.839G $>$ C, p.Arg280Pro (R280P) and c.86_88dup, p.Asp29_Arg30insHis (30:insH) positioned at quite distance from the "gating glutamate" induced similar disturbances. Respectively in HEK-MSR cells and in immortalized proximal tubular epithelial cells from patients with Dent disease 1 expressing those three ClC-5 mutants, authors were not able to see any abnormal endosomal acidification (Gorvin et al., 2013 ; Smith et al., 2009). However, defective receptor-mediated endocytosis was also observed with the 30:insH mutation, whereas fluid-phase endocytosis was unaffected. Several hypotheses have been proposed to explain the involvement of luminal $\mathrm{Cl}^{-}$in the endosomal pathway (Stauber \& Jentsch, 2013). Changes in $\mathrm{Cl}^{-}$ concentration may for instance affect $\mathrm{Ca}^{2+}$ efflux from members of the two-pore channel (TPC) family that are target for the second messenger nicotinic acid adenine dinucleotide phosphate (NAADP) or the transient receptor potential mucolipin (TRPML) family. These channels play a significant role in fusion and trafficking of the endo-lysosomal network by 
promoting local $\mathrm{Ca}^{2+}$ release (Brailoiu \& Brailoiu, 2016 ; Grimm, Butz, Chen, Wahl-Schott, \& Biel, 2017). Alternatively, because these organelles are highly permeable to water, alterations in luminal $\mathrm{Cl}^{-}$concentration may influence their shape via an osmotic effect. These changes could prevent formation of tubular membranes that are required for the formation or the fusion of endosomes and lysosomes (Scott \& Gruenberg, 2011).

In this context, further experiments using a vector encoding a protein-based Clsensitive probe specifically targeted to early endosomes would be needed to measure the impact on endosomal chloride concentration of the mutations that do not impair endosomal acidification (G57V, 30:insH, R280P and E211G). Unfortunately, such probe is still yet-tobe-developped: intracellular chloride reporters have been described but none of them are able to specifically reach endosomal compartments (Arosio \& Ratto, 2014; Gensch, Untiet, Franzen, Kovermann, \& Fahlke, 2015 ; Sulis Sato et al., 2017). These experiments will be necessary to unravel the importance of chloride accumulation in early endosomes and to determine if a reduced endosomal chloride concentration could be the cellular defect shared by all CLCN5 pathogenic mutations. In conclusion, it is possible that the physicochemical characteristics of amino acid changes could determine the mechanism involved in the physiopathology of mutations of the ClC-5 protein and on the consequences either on $\mathrm{Cl}^{-}$ accumulation, and / or on endosomal acidification. Such phenomenon could contribute to the absence of correlation of genotype-phenotype in Dent disease. 


\section{ACKNOWLEDGMENTS}

We thank Prof. Thomas J. Jentsch for kindly providing the HA-tagged ClC-5, Christophe Klein for excellent technical assistance in confocal microscopy, Gabrielle Planelles and Naziha Bakouh for support and help with oocytes. We also thank Marc Ambrosini and Yohan Legueux-Cajgfinger for their contributions during their graduate studies at Université Pierre et Marie Curie. This work was supported by the grant RAD16003DDA from the Fondation du Rein. Yohan Bignon holds a fellowship from the French Ministère de l'Enseignement Supérieur et de la Recherche. 


\section{REFERENCES}

Accardi, A., \& Miller, C. (2004). Secondary active transport mediated by a prokaryotic homologue of ClC Cl- channels. Nature, 427(6977), 803-7.

Alekov, A. K. (2015). Mutations associated with Dent's disease affect gating and voltage dependence of the human anion/proton exchanger ClC-5. Front Physiol, 6, 159.

Alekov, Alexi K., \& Fahlke, C. (2009). Channel-like slippage modes in the human anion/proton exchanger ClC-4. The Journal of General Physiology, 133(5), 485-496. https://doi.org/10.1085/jgp.200810155

Arosio, D., \& Ratto, G. M. (2014). Twenty years of fluorescence imaging of intracellular chloride. Frontiers in Cellular Neuroscience, 8, 258. https://doi.org/10.3389/fncel.2014.00258

Brailoiu, G. C., \& Brailoiu, E. (2016). Modulation of Calcium Entry by the Endo-lysosomal System. Advances in Experimental Medicine and Biology, 898, 423-447. https://doi.org/10.1007/978-3-319-26974-0_18

Crocker, J. C., \& Grier, D. G. (1996). Methods of digital video microscopy for colloidal studies. J Colloid Interface, 179, 298-310.

D’Antonio, C., Molinski, S., Ahmadi, S., Huan, L. J., Wellhauser, L., \& Bear, C. E. (2013). Conformational defects underlie proteasomal degradation of Dent's disease-causing mutants of ClC-5. Biochem J, 452(3), 391-400.

Devuyst, O., Christie, P. T., Courtoy, P. J., Beauwens, R., \& Thakker, R. V. (1999). Intrarenal and subcellular distribution of the human chloride channel, CLC-5, reveals a pathophysiological basis for Dent's disease. Hum Mol Genet, 8(2), 247-57.

Devuyst, O., \& Luciani, A. (2015). Chloride transporters and receptor-mediated endocytosis in the renal proximal tubule. J Physiol, 593(18), 4151-64.

Dutzler, R., Campbell, E. B., Cadene, M., Chait, B. T., \& MacKinnon, R. (2002). X-ray structure of a $\mathrm{ClC}$ chloride channel at 3.0 A reveals the molecular basis of anion selectivity. Nature, 415(6869), 287-94.

Dutzler, R., Campbell, E. B., \& MacKinnon, R. (2003). Gating the selectivity filter in ClC chloride channels. Science, 300(5616), 108-12.

Feng, L., Campbell, E. B., Hsiung, Y., \& MacKinnon, R. (2010). Structure of a eukaryotic CLC transporter defines an intermediate state in the transport cycle. Science, 330(6004), 635-41.

Friedrich, T., Breiderhoff, T., \& Jentsch, T. J. (1999). Mutational analysis demonstrates that ClC-4 and ClC-5 directly mediate plasma membrane currents. J Biol Chem, 274(2), 896-902.

Gensch, T., Untiet, V., Franzen, A., Kovermann, P., \& Fahlke, C. (2015). Determination of Intracellular Chloride Concentrations by Fluorescence Lifetime Imaging. Dans Advanced Time-Correlated Single Photon Counting Applications (pp. 189-211). (S.1.) : Springer, Cham. https://doi.org/10.1007/978-3-319-14929-5_4

Gorvin, C. M., Wilmer, M. J., Piret, S. E., Harding, B., van den Heuvel, L. P., Wrong, O., ... Thakker, R. V. (2013). Receptor-mediated endocytosis and endosomal acidification is impaired in proximal tubule epithelial cells of Dent disease patients. Proc Natl Acad Sci US A, 110(17), 7014-9.

Graham, F. L., \& van der Eb, A. J. (1973). A new technique for the assay of infectivity of human adenovirus 5 DNA. Virology, 52(2), 456-467. 
Grand, T., L'Hoste, S., Mordasini, D., Defontaine, N., Keck, M., Pennaforte, T., ... Lourdel, S. (2011). Heterogeneity in the processing of CLCN5 mutants related to Dent disease. Hum Mutat, 32(4), 476-83.

Grand, T., Mordasini, D., L'Hoste, S., Pennaforte, T., Genete, M., Biyeyeme, M. J., ... Lourdel, S. (2009). Novel CLCN5 mutations in patients with Dent's disease result in altered ion currents or impaired exchanger processing. Kidney Int, 76(9), 999-1005.

Grieschat, M., \& Alekov, A. K. (2014). Multiple discrete transitions underlie voltagedependent activation in $\mathrm{CLC} \mathrm{Cl}(-) / \mathrm{H}(+)$ antiporters. Biophysical Journal, 107(6), L13-15. https://doi.org/10.1016/j.bpj.2014.07.063

Grimm, C., Butz, E., Chen, C.-C., Wahl-Schott, C., \& Biel, M. (2017). From mucolipidosis type IV to Ebola: TRPML and two-pore channels at the crossroads of endo-lysosomal trafficking and disease. Cell Calcium. https://doi.org/10.1016/j.ceca.2017.04.003

Gunther, W., Luchow, A., Cluzeaud, F., Vandewalle, A., \& Jentsch, T. J. (1998). ClC-5, the chloride channel mutated in Dent's disease, colocalizes with the proton pump in endocytotically active kidney cells. Proc Natl Acad Sci U S A, 95(14), 8075-80.

Gunther, W., Piwon, N., \& Jentsch, T. J. (2003). The ClC-5 chloride channel knock-out mouse - an animal model for Dent's disease. Pflugers Arch, 445(4), 456-62.

Hamill, O. P., Marty, A., Neher, E., Sakmann, B., \& Sigworth, F. J. (1981). Improved patchclamp techniques for high-resolution current recording from cells and cell-free membrane patches. Pflugers Archiv: European Journal of Physiology, 391(2), 85100.

Hoopes, R. R., Jr., Shrimpton, A. E., Knohl, S. J., Hueber, P., Hoppe, B., Matyus, J., ... Scheinman, S. J. (2005). Dent Disease with mutations in OCRL1. Am J Hum Genet, 76(2), 260-7.

Hryciw, D. H., Ekberg, J., Pollock, C. A., \& Poronnik, P. (2006). ClC-5: a chloride channel with multiple roles in renal tubular albumin uptake. Int J Biochem Cell Biol, 38(7), 1036-42.

Hryciw, D. H., Jenkin, K. A., Simcocks, A. C., Grinfeld, E., McAinch, A. J., \& Poronnik, P. (2012). The interaction between megalin and $\mathrm{ClC}-5$ is scaffolded by the $\mathrm{Na}^{+}-\mathrm{H}^{+}$ exchanger regulatory factor 2 (NHERF2) in proximal tubule cells. The International Journal of Biochemistry \& Cell Biology, 44(5), 815-823. https://doi.org/10.1016/j.biocel.2012.02.007

Hryciw, D. H., Kruger, W. A., Briffa, J. F., Slattery, C., Bolithon, A., Lee, A., \& Poronnik, P. (2012). Sgk-1 is a positive regulator of constitutive albumin uptake in renal proximal tubule cells. Cellular Physiology and Biochemistry: International Journal of Experimental Cellular Physiology, Biochemistry, and Pharmacology, 30(5), 12151226. https://doi.org/10.1159/000343313

Jentsch, T. J. (2015). Discovery of CLC transport proteins: cloning, structure, function and pathophysiology. The Journal of Physiology. https://doi.org/10.1113/jphysiol.2014.270043

Lloyd, S. E., Pearce, S. H., Gunther, W., Kawaguchi, H., Igarashi, T., Jentsch, T. J., \& Thakker, R. V. (1997). Idiopathic low molecular weight proteinuria associated with hypercalciuric nephrocalcinosis in Japanese children is due to mutations of the renal chloride channel (CLCN5). J Clin Invest, 99(5), 967-74.

Lourdel, S., Grand, T., Burgos, J., Gonzalez, W., Sepulveda, F. V., \& Teulon, J. (2012). ClC5 mutations associated with Dent's disease: a major role of the dimer interface. Pflugers Arch, 463(2), 247-56.

Ludwig, M., Doroszewicz, J., Seyberth, H. W., Bokenkamp, A., Balluch, B., Nuutinen, M., ... Waldegger, S. (2005). Functional evaluation of Dent's disease-causing mutations: 
implications for ClC-5 channel trafficking and internalization. Hum Genet, 117(2-3), 228-37.

Mahon, M. J. (2011). pHluorin2: an enhanced, ratiometric, pH-sensitive green florescent protein. Advances in Bioscience and Biotechnology (Print), 2(3), 132-137. https://doi.org/10.4236/abb.2011.23021

Mansour-Hendili, L., Blanchard, A., Le Pottier, N., Roncelin, I., Lourdel, S., Treard, C., ... Vargas-Poussou, R. (2015). Mutation Update of the CLCN5 Gene Responsible for Dent Disease 1. Hum Mutat, 36(8), 743-52.

Matsuda, J. J., Filali, M. S., Collins, M. M., Volk, K. A., \& Lamb, F. S. (2010). The ClC-3 $\mathrm{Cl}-\mathrm{H}+$ antiporter becomes uncoupled at low extracellular pH. J Biol Chem, 285(4), 2569-79.

Miesenböck, G., De Angelis, D. A., \& Rothman, J. E. (1998). Visualizing secretion and synaptic transmission with $\mathrm{pH}$-sensitive green fluorescent proteins. Nature, 394(6689), 192-195. https://doi.org/10.1038/28190

Neagoe, I., Stauber, T., Fidzinski, P., Bergsdorf, E. Y., \& Jentsch, T. J. (2010). The late endosomal ClC-6 mediates proton/chloride countertransport in heterologous plasma membrane expression. J Biol Chem, 285(28), 21689-97.

Novarino, G., Weinert, S., Rickheit, G., \& Jentsch, T. J. (2010). Endosomal chloride-proton exchange rather than chloride conductance is crucial for renal endocytosis. Science, 328(5984), 1398-401.

Picollo, A., \& Pusch, M. (2005). Chloride/proton antiporter activity of mammalian CLC proteins ClC-4 and ClC-5. Nature, 436(7049), 420-3.

Piwon, N., Gunther, W., Schwake, M., Bosl, M. R., \& Jentsch, T. J. (2000). ClC-5 Cl- channel disruption impairs endocytosis in a mouse model for Dent's disease. Nature, 408(6810), 369-73.

Rasband, W. S. (n.d.). ImageJ US Natl Inst Health. https://imagej.nih.gov/ij/

Reed, A. A., Loh, N. Y., Terryn, S., Lippiat, J. D., Partridge, C., Galvanovskis, J., ... Thakker, R. V. (2010). CLC-5 and KIF3B interact to facilitate CLC-5 plasma membrane expression, endocytosis, and microtubular transport: relevance to pathophysiology of Dent's disease. Am J Physiol Renal Physiol, 298(2), F365-80.

Sakamoto, H., Sado, Y., Naito, I., Kwon, T. H., Inoue, S., Endo, K., ... Marumo, F. (1999). Cellular and subcellular immunolocalization of $\mathrm{ClC}-5$ channel in mouse kidney: colocalization with H+-ATPase. Am J Physiol, $277(6$ Pt 2), F957-65.

Satoh, N., Yamada, H., Yamazaki, O., Suzuki, M., Nakamura, M., Suzuki, A., ... Horita, S. (2016). A pure chloride channel mutant of CLC-5 causes Dent's disease via insufficient V-ATPase activation. Pflugers Archiv: European Journal of Physiology, 468(7), 1183-1196. https://doi.org/10.1007/s00424-016-1808-7

Scheel, O., Zdebik, A. A., Lourdel, S., \& Jentsch, T. J. (2005). Voltage-dependent electrogenic chloride/proton exchange by endosomal CLC proteins. Nature, 436(7049), 424-7.

Scott, C. C., \& Gruenberg, J. (2011). Ion flux and the function of endosomes and lysosomes: $\mathrm{pH}$ is just the start: the flux of ions across endosomal membranes influences endosome function not only through regulation of the luminal pH. BioEssays: News and Reviews in Molecular, Cellular and Developmental Biology, 33(2), 103-110. https://doi.org/10.1002/bies.201000108

Smith, A. J., \& Lippiat, J. D. (2010). Direct endosomal acidification by the outwardly rectifying CLC-5 $\mathrm{Cl}(-) / \mathrm{H}(+)$ exchanger. The Journal of Physiology, 588(Pt 12), 20332045. https://doi.org/10.1113/jphysiol.2010.188540 
Smith, A. J., Reed, A. A., Loh, N. Y., Thakker, R. V., \& Lippiat, J. D. (2009). Characterization of Dent's disease mutations of CLC-5 reveals a correlation between functional and cell biological consequences and protein structure. Am J Physiol Renal Physiol, 296(2), F390-7.

Stauber, T., \& Jentsch, T. J. (2013). Chloride in vesicular trafficking and function. Annual Review of Physiology, 75, 453-477. https://doi.org/10.1146/annurev-physiol-030212183702

Steinmeyer, K., Schwappach, B., Bens, M., Vandewalle, A., \& Jentsch, T. J. (1995). Cloning and functional expression of rat CLC-5, a chloride channel related to kidney disease. $J$ Biol Chem, 270(52), 31172-7.

Sulis Sato, S., Artoni, P., Landi, S., Cozzolino, O., Parra, R., Pracucci, E., ... Ratto, G. M. (2017). Simultaneous two-photon imaging of intracellular chloride concentration and $\mathrm{pH}$ in mouse pyramidal neurons in vivo. Proceedings of the National Academy of Sciences of the United States of America, 114(41), E8770-E8779. https://doi.org/10.1073/pnas.1702861114

Suzuki, T., Rai, T., Hayama, A., Sohara, E., Suda, S., Itoh, T., ... Uchida, S. (2006). Intracellular localization of $\mathrm{ClC}$ chloride channels and their ability to form heterooligomers. J Cell Physiol, 206(3), 792-8.

Tang, X., Brown, M. R., Cogal, A. G., Gauvin, D., Harris, P. C., Lieske, J. C., ... Chang, M.H. (2016). Functional and transport analyses of CLCN5 genetic changes identified in Dent disease patients. Physiological Reports, 4(8). https://doi.org/10.14814/phy2.12776

Wang, Y., Cai, H., Cebotaru, L., Hryciw, D. H., Weinman, E. J., Donowitz, M., ... Guggino, W. B. (2005). ClC-5: role in endocytosis in the proximal tubule. Am J Physiol Renal Physiol, 289(4), F850-62.

Weinert, S., Jabs, S., Supanchart, C., Schweizer, M., Gimber, N., Richter, M., ... Jentsch, T. J. (2010). Lysosomal pathology and osteopetrosis upon loss of H+-driven lysosomal Cl- accumulation. Science (New York, N.Y.), 328(5984), 1401-1403. https://doi.org/10.1126/science. 1188072 


\section{FIGURE LEGENDS}

Figure 1. Functional characterization of WT ClC-5 and E211G mutant in X. laevis oocytes. A: Representative voltage-clamp recordings obtained from oocytes expressing WT and E211G ClC-5, and from noninjected oocytes in ND96 solution. B: Steady-state currentvoltage relationships obtained under the same conditions as described in A. Each data point represents the mean \pm SEM for at least 8 oocytes from three different batches (WT, $n=19$; E211G, $n=17$; NI, $n=8$ ). C: Currents/cell surface expression relationship for WT ClC-5 and E211G mutant in $X$. laevis oocytes. Currents at $+100 \mathrm{mV}$ are from the same data as in panel A. For cell surface expression, the values (measured in RLU: Relative Light Units) were normalized to those of WT ClC-5 in the same batch of oocytes. Each column represents the mean \pm SEM for at least 8 oocytes for current recordings, and at least 40 oocytes from three different batches of oocytes for the surface expression. D: Extracellular $\mathrm{pH}$ dependence obtained from $X$. laevis expressing WT and E211G ClC-5 in ND96 solution at pH 5.5, 6.5, 7.0, 7.4 and 8.5. Currents at $+100 \mathrm{mV}$ were normalized for individual oocytes in the same batch of oocytes to the current at $+100 \mathrm{mV}$ in ND96 solution at $\mathrm{pH}$ 7.4. WT, oocytes injected with wild-type ClC-5; NI, noninjected oocytes. ${ }^{*}, P<0.001$ is the difference between WT or E211G ClC-5 versus NI. \#, $P<0.001$ is the difference between NI or E211G ClC-5 versus WT ClC-5. WT, oocytes injected with wild-type ClC-5; NI, noninjected oocytes.

Figure 2. Subcellular localization of WT ClC-5 and E211G mutant in HEK293T transfected cells. ClC-5 expression was detected by green fluorescence. Plasma membrane and early endosomes were stained by biotin and Early Endosome Antigen 1 marker (EEA1), and were detected by red fluorescence. The yellow fluorescence indicates the overlap of ClC-5 and the organelles. Scale bars, $8 \mu \mathrm{m}$. WT, wild-type. 
Figure 3. Cell surface biotinylation and western-blot analysis of WT ClC-5 and E211G mutant in HEK293T transfected cells. A: Results are shown as western blot analysis of the surface biotinylated protein fraction $(\mathrm{S})$ or total cell lysates $(\mathrm{T})$. The right panel shows densitometric analysis of total and cell surface ClC-5 as normalized expression to WT ClC-5. Each column represents the mean \pm SEM from four experiments. Mock refers to HEK293T cells transfected without the expression vector; WT and E211G refer to HEK293T cells transfected with WT or mutant ClC-5. B: Total cell lysates were isolated from HEK293T cells $48 \mathrm{~h}$ after transfection with ClC-5. Actin was used as the loading marker of the samples. The right panel shows semi-quantification of the blots by densitometry analysis. Protein expression was normalized to those of WT ClC-5. Each column represents the mean \pm SEM from three experiments.

Figure 4. Measurement of proton flux of WT ClC-5 and E211G mutant in HEK293T transfected cells. A: Representative whole-cell recording and B: current-voltage relationship obtained from HEK293T cells expressing E211G $(n=7)$ or E211Q C1C-5 $(n=10)$. Data are presented as mean \pm SEM. C: Representative intracellular $\mathrm{pH}$ changes recorded at different voltages in a HEK293T transfected cells expressing WT or E211G ClC-5 using BCECF fluorimetry. Lines represent linear fits to the data and were used to provide the rates of intracellular $\mathrm{pH}$ changes $\Delta p H / \Delta t$. The insets depict the macroscopic whole cell currents measured in the same cells. D: Averaged rates of intracellular $\mathrm{pH}$ changes as function of clamp voltage. The red line represents the scaled current-voltage relationship of WT ClC-5. Each data point represents the mean \pm SEM from 5 different cells. 
Figure 5. Effects of WT and E211G ClC-5 on endosomal acidification in HEK293T transfected cells. A: Representative confocal images as used for determining intracellular $\mathrm{pH}$. The large image represents the overlay of mCherry $\mathrm{ClC}-5$ (red fluorescence) and synaptopHluorin2 (green fluorescence). Scale bars, $10 \mu \mathrm{m}$. B: Illustration of the particle identification used to select individual vesicular regions in the red channel (ClC-5 containing endosomes) and used to measure the fluorescence intensities in both pHluorin2 channels. The identified particles are overlaid as circles on the red channel of the cells depicted in A. C: Endosomal $\mathrm{pH}$ measured from cells transfected with pHluorin2 (Mock, $n=55$ ) or with ClC-5 (WT, $n=30 ; \mathrm{E} 211 \mathrm{G}, n=41$ ). 


\section{A novel CLCN5 pathogenic mutation supports Dent'sDent disease with normal endosomal acidification}

Yohan Bignon ${ }^{1}$, Alexi Alekov ${ }^{2}$, Nadia Frachon ${ }^{1}$, Olivier Lahuna ${ }^{3}$, Carine Jean-Baptiste DohEgueli $^{4}$, Georges Deschênes ${ }^{5,6}$, Rosa Vargas-Poussou ${ }^{7,8}$ and Stéphane Lourdel ${ }^{1}$

${ }^{1}$ Sorbonne Université, Université Paris-Descartes, INSERM, CNRS, F-75006, Paris, France ; ${ }^{2}$ Institut für Neurophysiologie, Medizinische Hochschule Hannover, Hannover, Germany ; ${ }^{3}$ INSERM, Institut Cochin, Paris, France ; ${ }^{4} \mathrm{CHU}$ de Pointe-à-Pitre, Service de pédiatrie générale, Pointe-à-Pitre, France ; ${ }^{5}$ Assistance Publique-Hôpitaux de Paris, Hôpital Robert Debré, Service de Néphrologie Pédiatrique, Paris, France ; ${ }^{6}$ Centre de Référence des Maladies Rénales Héréditaires de l'Enfant et de l'Adulte (MARHEA), Paris, France ; ${ }^{7}$ Assistance Publique-Hôpitaux de Paris, Hôpital Européen Georges Pompidou, Département de génétique, Paris, France $;{ }^{8}$ Université Paris-Descartes, Faculté de Médecine, Paris, France.

\section{Corresponding author:}

Dr. Stéphane Lourdel

Centre de Recherche des Cordeliers UMR_S 1138, ERL 8228

15, rue de l'école de médecine, 75006 Paris, France

Phone : +331442751 17 Fax : +331442751 19

Email : stephane.lourdel@upmc.fr 


\section{ABSTRACT}

Dent'sDent disease in an X-linked recessive renal tubular disorder characterized by low-molecular-weight proteinuria, hypercalciuria, nephrolithiasis, nephrocalcinosis $\overline{\overline{ }}$, and progressive renal failure. Inactivating mutations of $C L C N 5$, the gene encoding the $2 \mathrm{Cl}^{-} / \mathrm{H}^{+}$ exchanger ClC-5 have been reported in patients with Dent'sDent disease 1. In vivo studies in mice harboring an artificial mutation in the "gating glutamate" of $\mathrm{ClC}-5$ (E211Ac.632A $>\mathrm{C}$, p.Glu211Ala) and mathematical modeling suggest that endosomal chloride concentration could be an important parameter in endocytosis, rather than acidification as earlier hypothesized. Here, we described a novel pathogenic mutation affecting the "gating glutamate" of ClC-5 (c.632A $>$ G, p.Glu211Gly)(E211G) and investigated its molecular consequences. In HEK293T cells, the p.Glu211GlyE211G ClC-5 mutant displayed unaltered eomplex $\mathrm{N}-\mathrm{N}$-glycosylation and-subsequent_normal plasma membrane and early endosomes localizations. In X. laevis oocytes and HEK293T cells, we found that contrasting with wildtype ClC-5-(WT), the mutation abolished the outward rectification, the sensitivity to extracellular $\mathrm{H}^{+}$and converted $\mathrm{ClC}-5$ into a $\mathrm{Cl}^{-}$channel. Investigation of endosomal acidification in HEK293 cells using the $\mathrm{pH}$-sensitive GFP variant $\mathrm{pH}$ Huorin2 probe showed that the luminal $\mathrm{pH}$ of cells expressing a Wwild-type $F$ or p.Glu211Gly E211G-ClC-5 was not significantly different. Our study further confirm $\underline{s}$ that impaired acidification of endosomes is not the only parameter leading to defective endocytosis in Bent's $\underline{\text { Dent }}$ disease 1.

Key words: Bent'sDent disease; $C L C N 5$; ClC-5; endosomal acidification; gating glutamate 


\section{INTRODUCTION}

Dent'sDent disease is a hereditary X-linked recessive renal proximal tubule disorder characterized by low-molecular-weight-proteinuria (LMWP), and hypercalciuria, inconstantly associated with other signs of Fanconi syndrome. Up to now, there is no specific treatment: Đent'sDent disease frequently led to nephrocalcinosis, nephrolithiasis and in many cases chronic renal failure. About two-third of patients display inactivating mutations of the CLCN5 gene (MIM\# 300008) encoding the $2 \mathrm{Cl}^{-} / \mathrm{H}^{+}$exchanger ClC-5 (Dent's $\underline{\text { Dent }}$ disease 1 , MIM-\#_300009), whereas inactivating mutations of the OCRL1 gene (MIM\# 300535) encoding the phosphatidylinositol-4,5-bisphosphate-5-phosphatase have been reported in $\sim 15 \%$ of patients (Đent'sDent disease 2, MIM_\#_300555) (Hoopes et al., 2005 ; MansourHendili et al., 2015). In the kidney, ClC-5 is abundantly expressed in the early endosomes of proximal tubule cells where it co-localizes with the V-type $\mathrm{H}^{+}$-ATPase and low-molecularweight proteins after their uptake by endocytosis. Lower levels of expression are also detected at the plasma membrane of these cells, in the thick ascending limb of Henle's loop and in $\alpha$-intercalated cells of the collecting duct (Devuyst, Christie, Courtoy, Beauwens, \& Thakker, 1999 ; Gunther, Luchow, Cluzeaud, Vandewalle, \& Jentsch, 1998 ; Piwon, Gunther, Schwake, Bosl, \& Jentsch, 2000 ; Sakamoto et al., 1999; Suzuki et al., 2006). The codistribution of $\mathrm{ClC}-5$ with the proton pump on early endosomes of proximal tubule cells suggested that it may play a crucial role in receptor-mediated endocytosis by permitting an electrical shunt required for sufficient endosomal acidification by the V-type $\mathrm{H}^{+}$-ATPase (Gunther et al., 1998 ; Piwon et al., 2000). Indeed, disturbed endosomal acidification and endocytosis were observed in ClC-5 knock-out mice (Gunther, Piwon, \& Jentsch, 2003 ; Novarino, Weinert, Rickheit, \& Jentsch, 2010 ; Piwon et al., 2000 ; Wang et al., 2005), in proximal tubule cell lines (Wang et al., 2005) and in immortalized proximal tubule cells from patients with Dent'sDent disease (Gorvin et al., 2013). The small amount of ClC-5 detected 
at the brush border of proximal tubule cells is also related to endocytosis, by mediating interactions with several proteins involved in receptor-mediated endocytosis, such as the multi-ligand receptor megalin and the microtubule-dependent motor protein KIF3B (Hryciw, Jenkin, et al., 2012 ; Hryciw, Kruger, et al., 2012 ; Hryciw, Ekberg, Pollock, \& Poronnik, 2006 ; Reed et al., 2010 ; Wang et al., 2005).

$\mathrm{ClC} 2 \mathrm{Cl}^{-} / \mathrm{H}^{+}$exchangers carry a critical glutamate residue that plays a key role in the coupling of $\mathrm{H}^{+}$to $\mathrm{Cl}^{-}$flux (Dutzler, Campbell, Cadene, Chait, \& MacKinnon, 2002 ; Dutzler, Campbell, \& MacKinnon, 2003; Feng, Campbell, Hsiung, \& MacKinnon, 2010). An artificial mutation of this "gating glutamate" to alanine in $\mathrm{ClC}-5$ (c.632A>C, p.Glu211Ala)(E211A) and in other $\mathrm{ClC}$ abolished $\mathrm{H}^{+}$flux and allowed the observation of pure $\mathrm{Cl}^{-}$conductance (Accardi \& Miller, 2004 ; Feng et al., 2010 ; Matsuda, Filali, Collins, Volk, \& Lamb, 2010 ; Neagoe, Stauber, Fidzinski, Bergsdorf, \& Jentsch, 2010 ; Picollo \& Pusch, 2005 ; Scheel, Zdebik, Lourdel, \& Jentsch, 2005). Interestingly, mice carrying the p.Glu211Ala (E211A) artificial mutation that converts ClC-5 to a pure $\mathrm{Cl}^{-}$channel displayed the same renal phenotype as ClC-5 knock-out, including LMWP proteinuria, despite normal endosomal acidification (Novarino et al., 2010). Model calculations indicate that such a $\mathrm{Cl}^{-}$ conductance may permit sufficient acidification, but leads to a reduced $\mathrm{Cl}^{-}$endosomal accumulation (Weinert et al., 2010).

It was also found in heterologous expression systems and in immortalized proximal tubule cells from patients that some CLCN5 mutations result in unaltered endosomal $\mathrm{pH}$ (Gorvin et al., 2013 ; Smith, Reed, Loh, Thakker, \& Lippiat, 2009). Altogether, these results suggest that endosomal chloride accumulation during $\mathrm{ClC}-5$ transport in proximal tubule cells may be critical in endocytosis, rather than acidification as first hypothesized. They also indicate that the role of $\mathrm{ClC}-5$ in the physiopathology of the disease is more complex than previously assumed. 
To date, at least 234 CLCN5 inactivating mutations have been identified in patients with Đent's Dent disease type 1 (Mansour-Hendili et al., 2015). Functional investigations using X. laevis oocytes and mammalian cells allowed the division of CLACN 5 missense mutations into three-different classes_(D’Antonio et al., 2013; Grand et al., 2009, 2011 ; Lourdel et al., 2012; Ludwig et al., 2005; Smith et al., 2009): the most frequent class includes mutations leading toelass 1 mutations are the most frequent, and induce a defect in protein folding and processing resulting in endoplasmic reticulum retention of the mutant protein for further degradation by the proteasome.; class 2 mutations cause a lower stability ef the mature protein; Another class of mutations and-class 3 mutations-alters electrical activity but not the trafficking of the mutant protein to the plasma membrane and the early endosomes.-- - Some mutations cause a delay in protein processing and reduce the stability of the mature form. Finally, three mutations have been described which surprisingly do not affect endosomal acidification (Gorvin et al., 2013 ; Smith et al., 2009).

In this study, we report clinical data describing the phenotype of a Dent's $\underline{\text { Dent }}$ disease 1 young patient carrying a novel pathogenic CLCN5 missense mutation $\underline{\text { c. } 632 \mathrm{~A}>\mathrm{G} \text {, }}$ pGlu211Gly (E211G) affecting the critical "gating glutamate" of ClC-5. We haveBy further investigateding the molecular consequences of such a mutation on $\mathrm{ClC}-5$ electrophysiological properties and on endosomal acidification, using X. laevis oocytes and HEK293T cells, ${ }_{\overline{-}}$. Our results support the existence of $\mathrm{ClC}-5$ mutations that do not lead to defective endosomal $\underline{\text { acidification despite their association with all classical clinical features of Dent disease. Such }}$ type of mutations further wighlights the potential importance of endosomal chloride concentration for proximal tubule cells endocytosis. 


\section{MATERIAL AND METHODS}

\section{DNA sequence analysis of the $C L C N 5$ gene}

Peripheral blood samples were obtained from the patient and genomic DNA was extracted by standard methods. The coding exons (2 to 12) and intron-exon junctions were amplified with $C L C N 5$-specific primers described elsewhere using PCR amplification (Lloyd et al., 1997). We carried out direct sequencing using the dioxy chain termination method on an automated Division 373A Stretch DNA capillary sequencer (Perkin Elmer/Applied Biosystems, CA, USA), and evaluated sequences with Sequencher software (Gene Codes, MI, USA). For in silico analysis we used Alamut V.2.10 software (Interactive Biosoftware, Rouen, France; http://www.interactivebiosoftware.com), which includes splice site predictions algorithms (SpliceSiteFinder, MaxEntScan NNSPLICE, GeneSplicer and HumanSplicingFinder). The variant reported in this article has been submitted to LOVD v.3 database at www.lovd.nl/CLCN5.

The patient belongs to a study that was approved by the "Comité de Protection des Personnes, Paris-Île de France XI (Ref. 09069)” and informed consent for genetic studies was obtained from his parents.

\section{Molecular Biology}

The human coding sequence of wild-type ClC-5 (GenBank NMG_000084.4007159.2) was subcloned either into the pTLN vector (a generous gift of Dr. Thomas J. Jentsch, MDC/FMP, Berlin, Germany) for expression in X. laevis oocytes, or into the peGFP and pRcCMV vectors for expression in HEK293T. In the peGFP vector, the coding sequence for

GFP have has been substituted for those of ClC-5. The HA epitope (YPYDVPDYA) is introduced between amino acids 107 and 108 of ClC-5 in pTLN and pEGFP vectors, or between amino acids 392 and 393 in the pRcCMV vector containing the fluorescent mCherry 
fused to the C-terminus of ClC-5, as previously described (Grand et al., 2011 ; Grieschat \& Alekov, 2014). The C1C-5 c.632A>G E211G mutation_-(E211G) was introduced in those vectors by site-directed mutagenesis using the Quickchange site-directed mutagenesis kit (Stratagene, CA, USA). All constructs were fully sequenced before use. The synaptopHluorin2 construct was kindly provided by Dr. Raul Guzman (FZ Jülich, Jülich, Germany). For its creation, we used the original vesicular $\mathrm{pH}$ reporter synapto-pHluorin kindly provided by Dr. Miesenböck (Miesenböck, De Angelis, \& Rothman, 1998). In our construct, we replaced the fluorescent GFP-based pHluorin with the newer and brighter pHluorin2 (Mahon, 2011) obtained as a gift from Dr. Mahon. Finally, the synapto-pHluorin2 sequence was subcloned into the p156rrL vector using standard PCR procedures.

\section{Expression in $X$. laevis oocytes}

Capped cRNA were synthetized in vitro from pTLN expression vectors using the SP6 mMessage mMachine Kit (Ambion, TX, USA). Defolliculated X. laevis oocytes were injected with $50 \mathrm{nl}$ of RNAse free-water containing $20 \mathrm{ng}$ of the different cRNAs and were then kept at $17^{\circ} \mathrm{C}$ in modified Barth's solution containing (in $\mathrm{mM}$ ): $88 \mathrm{NaCl}, 1 \mathrm{KCl}, 0.41$ $\mathrm{CaCl}_{2}, 0.33 \mathrm{Ca}\left(\mathrm{NO}_{3}\right)_{2}, 0.82 \mathrm{MgSO}_{4}, 10$ HEPES, pH 7.4, and supplemented with $10 \mathrm{U} / \mathrm{ml}$ of penicillin and $10 \mu \mathrm{g} / \mathrm{ml}$ streptomycin (ThermoFischer, MA, USA).

\section{Surface labeling of oocytes}

Experiments were performed as previously described (Grand et al., 2011). Briefly, a rat monoclonal anti-HA antibody (3F10, Roche Diagnostics, France) was used as primary antibody and a peroxidase-conjugated goat anti-rat antibody (Jackson ImmunoResearch, PA, USA) as secondary antibody. Chemiluminescence was quantified using a Turner TD-20/20 
luminometer (Turner Designs, CA, USA) by placing individual oocytes in $50 \mu 1$ of SuperSignal Elisa Femto Maximum Sensitivity Substrate Solution (Pierce, IL, USA).

\section{Voltage-clamp in $X$. laevis oocytes}

Two days after injection, two-electrode voltage-clamp experiments were performed at room temperature using a TEV-200A amplifier (Dagan, MN, USA) and PClamp 10 software (Axon Instruments, CA, USA). Currents were recorded in ND96 solution containing (in $\mathrm{mM}): 96 \mathrm{NaCl}, 2 \mathrm{KCl}, 1.5 \mathrm{CaCl}_{2}, 1 \mathrm{MgCl}_{2}, 5$ HEPES, pH 7.4. For $\mathrm{pH}$ 5.5, 6.5 and 7.0, $5 \mathrm{mM}$ HEPES was replaced by $5 \mathrm{mM}$ MES. For pH 8.5, $5 \mathrm{mM}$ HEPES was replaced by $5 \mathrm{mM}$ Trizma Base. Currents were recorded in response to a voltage protocol consisting of $20 \mathrm{mV}$ steps from $-100 \mathrm{mV}$ to $+100 \mathrm{mV}$ during $800 \mathrm{~ms}$ from a holding potential of $-30 \mathrm{mV}$.

\section{Whole-cell recordings}

An EPC-10 amplifier controlled by the PATCHMASTER software package (both from HEKA Electronics), was used to perform whole-cell patch-clamp (Hamill, Marty, Neher, Sakmann, \& Sigworth, 1981). Currents were recorded after filtering at $3 \mathrm{kHz}$ and digitalization at $100 \mathrm{kHz}$ sampling rate. To reduce series resistance voltage errors, capacitance cancelation and series resistance compensation were applied. Recordings for which the uncompensated error exceeded $5 \mathrm{mV}$ were discarded. Patch pipettes with resistances between 1.2-1.8 $\mathrm{M} \Omega$ were filled with a patch pipette solution containing (in $\mathrm{mM}$ ): $110 \mathrm{NaCl}, 5 \mathrm{MgCl}_{2}, 5$ EGTA and 10 HEPES ( $\mathrm{pH}$ 7.4). The standard extracellular solution contained (in $\mathrm{mM}$ ) $145 \mathrm{NaCl}, 4 \mathrm{KCl}, 2 \mathrm{CaCl}_{2}, 1 \mathrm{MgCl}_{2}$, and $15 \operatorname{HEPES}(\mathrm{pH} 7.4$ ). 


\section{Cell culture and transfection}

HEK293T cells used for biochemistry were grown at $37^{\circ} \mathrm{C}$ and $5 \% \mathrm{CO}_{2}$, in Dulbecco's Modified Eagle's Medium (Gibco, CA, USA) supplemented with $10 \%$ fetal bovine serum (Eurobio, France) and a penicillin/streptomycin mix (ThermoFischer, MA, USA) to a final concentration of $100 \mathrm{U} / \mathrm{ml}$ and $100 \mathrm{mg} / \mathrm{ml}$, respectively. The cells were transiently transfected with 1 ug of pEGFP plasmid using X-tremeGENE 9 DNA transfection Reagent (Sigma Aldrich, MO, USA) according to the manufacturer's instructions.

HEK 293 T cells used for electrophysiology and vesicular $\mathrm{pH}$ measurements were cultured in DMEM (Gibco, CA, USA) supplemented with 10\% FBS (Biochrom AG, Germany), 2 mM L-glutamine and 50 units/ml penicillin/streptomycin (ThermoFischer, MA, USA). Cells were transfected using standard calcium phosphate precipitation method (Graham \& van der Eb, 1973) using $10 \mu \mathrm{g}$ of pRcCMV-ClC-5 DNA alone or in combination with $5 \mu$ g synapto-pHluorin2 plasmid.

\section{Surface biotinylation of HEK293T cells}

Forty-eight hours after transfection, cells were placed 30 minutes on ice and rinsed three times with a cold PBS solution $\mathrm{pH} 8.0$ supplemented with $100 \mathrm{mM} \mathrm{CaCl}$ and $1 \mathrm{mM}$ $\mathrm{MgCl}_{2}$ (PBS++). Cells were then incubated at $4^{\circ} \mathrm{C}$ for 1 hour with $1.5 \mathrm{mg} / \mathrm{ml}$ biotin in cold PBS $++\mathrm{pH}$ 8.0. After 1 hour at $4^{\circ} \mathrm{C}$ in a quenching solution, cells were washed three times in ice cold PBS++. When surface biotinylation was followed by western blotting analysis, the biotin and the quenching solutions contained the reducible Sulfo-NHS-SS-biotin (Pierce, IL, USA) and $0.1 \%$ BSA in PBS++, respectively. When surface biotinylation was followed by immunocytochemistry, the biotin and the quenching solutions contained the non-reducible Sulfo-NHS-LC-biotin (Pierce, IL, USA) and $100 \mathrm{mM}$ Glycine in PBS++ pH 8.0, respectively. 


\section{Total and surface protein isolation}

Forty-eight hours after transfection, cells were incubated and scratched at $4{ }^{\circ} \mathrm{C}$ in a lysis solution containing $150 \mathrm{mM} \mathrm{NaCl}, 50 \mathrm{mM}$ Tris-HCl, $1 \mathrm{mM}$ EDTA, $1 \%$ NP-40, $0.2 \%$ SDS pH 7.4 and a Complete EDTA Free protease inhibitor mix (Roche Diagnostics, France). Extracts turned 30 minutes at $4{ }^{\circ} \mathrm{C}$ on a wheel to solubilize proteins and were then centrifuged at $5000 \mathrm{~g}$ during 10 minutes. Protein concentration in the resulting supernatant was quantified using the BCA Protein Assay quantification kit (Pierce, IL, USA). For protein extraction from surface-biotinylated HEK293T cells, lysis solution contained $50 \mathrm{mM}$ Tris-HCl, $2 \mathrm{mM}$ EDTA, $2 \mathrm{mM}$ EGTA, $30 \mathrm{mM} \mathrm{NaF}, 30 \mathrm{mM}$ NaPPi, 1\% Triton and 0.1\% SDS and a Complete EDTA Free protease inhibitor mix (Roche Diagnostics, France). Protein extracts were subjected to centrifugation during 3 minutes at $15000 \mathrm{~g}$.

Isolation of biotinylated proteins was performed using $100 \mu \mathrm{g}$ of fresh total protein extracts from surface-biotinylated HEK293T cells and NeutrAvidin-agarose beads (Pierce, IL, USA). For each reaction, washed and dried beads from $110 \mu 1$ of the provided $50 \%$ slurry were diluted into $500 \mu \mathrm{l}$ of a TLB solution containing (in $\mathrm{mM}$ ): 50 Tris $\mathrm{HCl}, 100 \mathrm{NaCl}, 5$ EDTA and a Complete EDTA Free protease inhibitor mix (Roche Diagnostics, France) and mixed with biotinylated protein extract. After overnight agitation at $4^{\circ} \mathrm{C}$, beads were centrifuged 2 minutes at $2500 \mathrm{~g}$ and were washed with TLB solution four times, to remove non-biotinylated proteins in the supernatant. Finally, dried beads were incubated 10 minutes at $95^{\circ} \mathrm{C}$ with $50 \mu \mathrm{l}$ of denaturing buffer, vortexed, centrifuged 2 minutes at $2500 \mathrm{~g}$ and $35 \mathrm{ul}$ from supernatant of denatured surface proteins were loaded in a polyacrylamide gel well. 


\section{Western blot analysis}

Twenty micrograms of total proteins or total surface protein extracts were separated on an $10 \%$ SDS-PAGE gel and transferred to nitrocellulose membranes. The blocking solution contained $5 \%$ of non-fat milk proteins added in the washing buffer TBS $+0.2 \%$ NP-40. Primary antibodies were monoclonal 3F10 rat anti-HA (Roche Diagnostics, France; 1:1500) and monoclonal A2228 mouse anti- $\beta$-Actine (Sigma Aldrich, MO, USA; 1:20000). Peroxidase-conjugated secondary antibodies were goat anti-rat antibody (Jackson ImmunoResearch, PA, USA; 1:10000) and sc-2005 goat anti-mouse (Santa Cruz; 1:10000). Antibodies were diluted in TBS blocking solution and incubated with membrane under constant agitation, overnight at $4^{\circ} \mathrm{C}$ or 1 hour at room temperature. Indirect protein detection was performed by chemiluminescence using the Pierce ${ }^{\mathrm{TM}}$ ECL Western Blotting Substrate (ThermoFischer, MA, USA). The protein signal was quantified using the ImageJ freeware (NIH, Bethesda, USA) and normalized on the $\beta$-actin signal (used as loading control).

\section{Immunocytochemistry and confocal Imaging}

Forty-eight hours after transfection on poly-L-lysine coated coverslips, HEK293T cells were washed with PBS, fixed in $4 \%$ paraformaldehyde and permeabilized with $0.1 \%$ Triton. Nonspecific binding sites were blocked with a $10 \%$ goat serum solution, in which antibodies were then incubated with cells during 1 hour at room temperature. Primary antibodies were H3663 mouse anti-HA (Sigma Aldrich, MO, USA; 1:200), Ab2900 rabbit anti-EEA1 (Abcam, Cambridge, UK; 1:200) and secondary antibodies were 115-095 FITCconjugated goat anti-mouse (Jackson ImmunoResearch, PA, USA; 1:250), A21428 AlexaFluor ${ }^{\mathrm{TM}} 555$-conjugated goat anti-rabbit (ThermoFischer, MA, USA); 1:250). In the course of surface biotin labelling, cells were biotinylated as described above, extra biotin was removed and cells were washed prior to chemical fixation with PFA. At the end of 
immunocytochemistry, Cy5-conjugated Streptavidin (ThermoFischer, MA, USA; 1:200) was incubated with cells in the same time than A11059 rabbit anti-mouse AlexaFluor ${ }^{\mathrm{TM}} 488$ conjugated antibody (Life Technologies; 1:200). Labeled cells were analyzed with a Zeiss LSM 710 confocal laser-scanning microscope.

\section{Fluorescence measurements of intracellular pH}

Measurements of intracellular $\mathrm{pH}$ in the whole-cell patch clamp configuration were described in detail elsewhere (Alekov \& Fahlke, 2009). In brief, cells were loaded with 37.5 $\mu \mathrm{M} \quad$ 2',7'-bis(2-carboxyethyl)-5(and 6)-carboxyfluorescein (BCECF, Wako Chemicals) through the patch pipette. For these experiments, the proton buffering capacity of the intracellular patch-clamp solution (see above) was lowered by reducing its HEPES content to $0.25 \mathrm{mM}$. BCECF fluorescence was detected through an UPlanSApo 60x/NA1.35 oil immersion objective mounted on an Olympus IX-71 microscope. Sequential excitation at 490 and $440 \mathrm{~nm}$ was applied using a Polychrome $\mathrm{V}$ monochromator and the fluorescence was detected at $530 \mathrm{~nm}$ with a photodiode (both from Till Photonics). The resultant fluorescence ratio F490/F440 was converted to absolute $\mathrm{pH}$ by using a calibration curve, previously obtained ex situ (see description in (Alekov \& Fahlke, 2009)).

\section{Vesicular pH measurement and confocal Imaging}

Ratiometric measurements of vesicular $\mathrm{pH}$ were performed as described previously (Alekov, 2015). In brief, WT or mutant ClC-5 were co-expressed with synapto-pHluorin2 in HEK293T cells. The fluorescence of an mCherry tag covalently linked to the C-terminus of the $\mathrm{ClC}$ transporter was used to identify vesicles containing $\mathrm{ClC}-5$. Subsequently, the $\mathrm{pH}$ in these vesicles was determined ratiometrically using a dual wavelength excitation of the fluorescent pHluorin2 construct containing a covalently linked fused synapto-pHlyuorin2. 
Images were acquired 24-48 $\mathrm{h}$ after transfection on a Carl-Zeiss LSM 780 inverted microscope using a 40x water immersion objective. The pHluorin2 and mCherry fluorophores were excited at 405/488 and $561 \mathrm{~nm}$ and emission was detected at 500-550 and 560-650 nm, respectively. Live cell imaging was performed in PBS containing $\mathrm{Ca}^{2+}$ and $\mathrm{Mg}^{2+}$ (Gibco, CA, USA) at room temperature $\left(22-24^{\circ} \mathrm{C}\right)$. A calibration curve was constructed to convert the ratio of the pHluorin2 fluorescence as excited with 405 and $488 \mathrm{nM}$ in absolute pH. To this end, cells were bathed in potassium-based solutions with different $\mathrm{pHs}$ supplemented with $10 \mu \mathrm{M}$ nigericin. The analysis of the calibration data was performed using Carl Zeiss Zen lite 2011 (Blue edition) software. Particle detection was performed using the MatLab (MathWorks) adaptation by Blair and Dufresne of the original Crocker and Grier algorithm (Crocker \& Grier, 1996). The code was incorporated into house-written MatLab script (Alekov, 2015) that carried out automatic background subtraction, segmentation ratiometric analyses of the identified vesicular regions. Images were assembled for figure visualization with IMAGEJ (Rasband, n.d.).

\section{Statistics}

Results are given as means \pm SEM for the indicated $n$ number of experiments. A significance difference between means was considered when a $\mathrm{P}$ value $<0.05$ was obtained after running a bilateral Student's $t$ test. 


\section{RESULTS \\ E211G mutation causes progressive Dent disease type 1 in a young patient}

The patient is the first son of unrelated parents. He was born at term of 39 weeks after an uneventful pregnancy, with body weight of 3,070 g and height of $48 \mathrm{~cm}$. At 4 months of age, failure to thrive was observed. At one year and a half, he was hospitalized for severe dehydration ( $>10 \%$ BW) with hyponatremia, hypokalemia, hypouricemia and hypophosphatemia (Table 1). Renal Ultrasound showed no nephrocalcinosis. He received intravenous rehydration and ambulatory treatment with salt and phosphate supplementation. Four months later, an hospitalization in a tertiary care center showed failure to thrive, similar electrolyte abnormalities and the urinary analysis suggested a diagnosis of Fanconi syndrome due to the association of salt loosing with secondary hyperaldosteronism, renal hypokalemia and hypouricemia, aminoaciduria, hypercalciuria, low molecular weight proteinuria (LMWP) and stage 2 CKD: eGFR (estimated glomerular filtration rate) was $78 \mathrm{ml} / \mathrm{mn} / 1.73 \mathrm{~m}^{2}$. X-ray examination show a bone age concordant with chronological age and no rickets.

The diagnosis of cystinosis was excluded (intraleucocytary cystine at $0.23 \mathrm{nmol} / \mathrm{mg}$, no cysteine crystals in retina or cornea and normal sensitivity to light) and diagnosis of Đent'sDent disease was considered. Direct sequencing of CLCN5 gene from peripheral genomic DNA reveals a c.632A $>$ G, p.Glu211Gly (E211G) mutation-variation in the coding exon 6. This missense change is predicted in silico as pathogenic and does not induced modification in the splice site scores. Family screening showed no LMWP and mild hypercalciuria in his mother (Table 1). Unfortunately, the compliance to treatment and to medical follow-up of this patient and his family is poor and in the last years he has only consulted to the emergency services twice during acute episodes associated with dehydration. At last follow-up, his eGFR calculated by Schwartz formula was $55 \mathrm{ml} / \mathrm{min} / 1.73 \mathrm{~m}^{2}$. 


\section{E211G mutation alters currents and sensitivity to external pH}

To characterize functionally the ClC-5 E211G mutant, we first injected wild-type (WT) and mutant human ClC-5 cRNA into X. laevis oocytes (Figure 1). Two electrode voltage-clamp recordings revealed typical strongly outwardly rectifying currents for the oocytes expressing WT ClC-5 (Friedrich, Breiderhoff, \& Jentsch, 1999 ; Grand et al., 2009, 2011 ; Picollo \& Pusch, 2005; Scheel et al., 2005; Steinmeyer, Schwappach, Bens, Vandewalle, \& Jentsch, 1995). In contrast, we observed that the E211G mutant displayed a nearly linear current/voltage relationship as already described for the artificial E211A and the recently described pathogenic c.631G $>$ C, p.Glu211Gln (E211Q) mutants (Friedrich et al., 1999 ; Picollo \& Pusch, 2005 ; Satoh et al., 2016 ; Scheel et al., 2005) (Figure 1A-B). The currents recorded with the E2 $11 \mathrm{G}$ mutant were significantly reduced by $38 \%$ in comparison to those of $\mathrm{WT} \mathrm{ClC}-5$ at positive membrane voltages. To further elucidate the mechanisms leading to reduced electrical activity, we investigated the plasma membrane targeting of the ClC-5 mutant using a chemiluminescence assay by taking advantage of the extracellular HA epitope on $\mathrm{ClC}-5$. We found that the normalized luminescence responses did not significantly differ between WT ClC-5 and the E211G mutant (Figure 1C). Thus, the reduced current amplitude of the mutant cannot be attributed to reduced cell surface expression. Furthermore, as previously reported (Friedrich et al., 1999 ; Picollo \& Pusch, 2005 ; Scheel et al., 2005), currents from WT ClC-5 were reduced by an extracellular acidification. Conversely, currents from the E211G mutant did not responded to extracellular pH changes (Figure 1D).

\section{E211G mutation hașve no effect on plasma membrane and early endosomes localization}

To further document the subcellular localization of the mutant $\mathrm{ClC}-5$, we performed confocal microscopy imaging in transiently-transfected HEK293T cells, a mammalian cell 
line that is appropriate for such analysis (Alekov, 2015 ; Grand et al., 2009, 2011 ; Satoh et al., 2016). As previously reported (Alekov, 2015 ; Grand et al., 2009, 2011 ; Smith et al., 2009 ; Tang et al., 2016), Figure 2 shows that WT ClC-5 co-localized with biotinylated cellsurface proteins, and with the early endosomes marker EEA1. Similarly, the C1C-5 E211G mutant co-localized with biotinylated cell-surface proteins and EEA1 (Figure 2). We also carried out surface biotinylation experiments using transiently-transfected HEK293T cells to further explore the plasma membrane expression of the mutant ClC-5. No significant differences could be detected in the surface fraction containing WT ClC-5 and the E211G mutant (Figure 3A). Overall, these data indicate that the E211G mutation lead to normal plasma membrane and early endosomes expression of ClC-5.

\section{E211G mutation does not result in altered protein expression and maturation}

We next examined the impact of the E211G mutation on ClC-5 protein expression. Total cell lysates isolated from HEK293T cells transfected transiently with WT or mutant ClC-5 were subjected to a western blot analysis (Figure 3B). In agreement with previous reports (Grand et al., 2009, 2011), WT ClC-5 expression produced two main immunoreactive signals at $\sim 75$ and $\sim 80-90 \mathrm{kDa}$. The lower band corresponds to the core-glycosylated form of $\mathrm{ClC}-5$ that is retained in the endoplasmic reticulum, whereas the upper band corresponds to the complex-glycosylated form of $\mathrm{ClC}-5$ that is present at the plasma membrane. Here, when an equivalent amount of proteins was loaded in each lane, we observed no quantitative or qualitative signal difference between WT ClC-5 and the E211G mutant. Thus, the E211G does not change the stability or N-glycosylation of ClC-5. 


\section{E211G mutation uncouples $\mathrm{Cl}^{-} / \mathrm{H}^{+}$exchange}

Overall, our results demonstrate that the E211G mutation does not alter the subcellular localization and protein expression of $\mathrm{ClC}-5$, but leads to an alteration of its function. Interestingly, the insensitivity of the E211G mutant to extracellular acidification reported in X. laevis oocytes (Figure 1D) was similar to data obtained for the E211A and E211Q mutants and thus suggests that the mutation may convert ClC-5 into a pure chloride conductance by eliminating the coupling of the $\mathrm{H}^{+}$currents to the $\mathrm{Cl}^{-}$flux (Picollo \& Pusch, 2005 ; Satoh et al., 2016; Scheel et al., 2005). Therefore, we then investigated proton transport of the mutant in HEK293T transfected cells. For this purpose, we measured the variations of the intracellular $\mathrm{pH}$ of cells expressing WT or E211G ClC-5 upon membrane depolarization by using the ratiometric $\mathrm{pH}$-sensitive fluorescent indicator BCECF. The plasma membrane was patch-clamped and subjected to different voltages using the wholecell configuration. Similar to recordings in $X$. laevis oocytes, currents obtained with the E211G mutant exhibited abolished outward rectification. Currents from the previously reported ClC-5 E211Q mutant (Satoh et al., 2016) were significantly lower compared to those of the E211G mutant (Figure 4A-B). In contrast to data recorded with WT ClC-5, exposure of transfected cells with the E211G mutant to positive membrane voltages did not lead to significant voltage-dependent intracellular $\mathrm{pH}$ changes (Figure 4C). The voltage-dependence of the rate of the intracellular $\mathrm{pH}$ change of cells expressing WT ClC- 5 correlated well with the voltage-dependence of the currents obtained with WT ClC-5 (Figure 4D). Such relationship could not be obtained with the ClC-5 E211G mutant despite significant currents at positive and negative membrane voltages in HEK293T cells. These results therefore demonstrate that the $\mathrm{ClC}-5 \mathrm{E} 211 \mathrm{G}$ mutant behaves as a pure $\mathrm{Cl}^{-}$channel. 


\section{E211G mutation results in unaltered endosomal acidification}

The localization of ClC-5 in early endosomes suggests an involvement in proximal tubule endocytosis by permitting intraluminal acidification, in agreement with the LMWP that is observed in patients with Dent'sDent disease (Devuyst \& Luciani, 2015). Thus, we next investigated the effect of the $\mathrm{E} 211 \mathrm{G}$ mutation on endosomal acidification in transfected HEK293 T cells using the $\mathrm{pH}$-sensitive GFP variant pHluorin2 fused to the C-terminus of the vesicular protein synaptobrevin (Alekov, 2015). As expected from a previous report (Alekov 2015), ClC-5 and synapto-pHluorin2 showed endosomal co-localization (Figure 5A). The analysis of ClC-5-containing endosomes (Figure 5B) showed that the E211G mutation lead to endosomal acidification ( $\mathrm{pH} 6.39 \pm 0.05, n=41)$ that was not significantly different to those elicited by WT ClC-5 (pH $6.24 \pm 0.06, n=30$ ) (Figure 5C). Endosomal pH was, however, significantly different between mock cells and cells expressing WT ClC-5 or the E211G mutant. Thus, E211G ClC-5 is still able to mediate proper early endosomal acidification. 


\section{DISCUSSION}

Here, we report a novel ClC-5 mutation (E211G) found in a young patient with Dent'sDent disease 1. Because the mutation affects the critical "gating glutamate" that is responsible for coupling the $\mathrm{Cl}^{-}$flux to the $\mathrm{H}^{+}$counter-transport in $\mathrm{ClC}-5$, we investigated in vitro its functional consequences.

Using voltage-clamp recordings in $X$. laevis oocytes, we showed that the outward rectification and the sensitivity to extracellular $\mathrm{H}^{+}$were abolished in the E211G mutant in contrast to WT ClC-5. Such alterations in ion conduction have already been observed for the artificial E211A and the pathogenic E211Q mutations. These amino acid substitutions directly affect the "gating glutamate" and lead $\mathrm{ClC}-5$ to function as a $\mathrm{Cl}^{-}$channel (Picollo \& Pusch, 2005 ; Satoh et al., 2016 ; Scheel et al., 2005). Consistent with these observations, we have also demonstrated that this mutant $\mathrm{ClC}-5$ behaves as a pure $\mathrm{Cl}^{-}$channel. Furthermore, the mutant displayed similar protein processing, plasma membrane and early endosomes distribution than WT ClC-5. Unaltered subcellular localization has already been described for the E211Q mutant, except that higher protein expression levels were reported for this mutant (Satoh et al., 2016).

It is postulated that defect in endosomal acidification consecutive to the loss-offunction of $\mathrm{ClC}-5$ is of crucial importance for proper proximal tubule endocytosis (Devuyst \& Luciani, 2015; Jentsch, 2015). Remarkably, using the ratiometric pH-sensitive GFP variant pHluorin2 in HEK293T cells, we demonstrated that the E211G mutation is not associated with defective endosomal acidification, given that the mean intraluminal $\mathrm{pH}$ did not significantly differ between cells expressing WT or the mutant ClC-5. This result is in sharp contrast with previous findings reported for endosomal acidification in HEK293T cells expressing the E211Q mutant. Despite unaltered early endosomes targeting of the mutant protein, the vesicular $\mathrm{pH}$ of these cells was significantly higher compared to cells expressing 
WT ClC-5 (Satoh et al., 2016). Changes in current amplitudes of the mutant proteins could explain this difference. Indeed, E211G and E211A produce currents amplitude moderately reduced compared to that of WT ClC-5 (Picollo \& Pusch, 2005). Conversely, our recordings in HEK293T cells demonstrated that the E211Q mutation results in dramatically lower currents compared to those of the E $211 \mathrm{G}$ mutant. Thus, the change of the acidic amino acid E for a polar uncharged amino acid as $\mathrm{Q}$, induces lower currents than the change for a hydrophobic amino acid as $\mathrm{G}$ or $\mathrm{A}$. In addition, $\mathrm{Q}$ and $\mathrm{E}$ have larger side chain compared with other studied amino acids and particularly with $\mathrm{G}$ and A, which are the two smallest amino acids. It seems, therefore, that not only the charge of the amino acid side chain at position 211 but also its size is are important for the biophysical properties of ClC-5. Furthermore, in vitro E211Q and E211A are is -associated with defective endosomal acidification while E211G and E211A exhibit normal acidification_(Satoh et al., 2016 ; Smith \& Lippiat, 2010). ClC-5 mutants with large electrically neutral side chain at position 211 (such as E211Q) might, therefore, exhibit insufficient electrical activity and reduce thereby the electrical shunt required by the V-type $\mathrm{H}^{+}$-ATPase. This would inhibit further $\mathrm{H}^{+}$ pumping by the $\mathrm{V}$-type $\mathrm{H}^{+}$-ATPase, and the vesicular $\mathrm{pH}$ would be quite distant from its physiological value. Interestingly, our findings are similar with data previously generated by Jentsch's group using the E211A mouse model (Novarino et al., 2010). Despite normal acidification of isolated early endosomes from the renal cortex, these mice displayed impaired proximal tubule endocytosis that was comparable to that observed in ClC-5 knockout mice. Such phenotype was ascribed to reduced $\mathrm{Cl}^{-}$concentration in endosomes resulting during acidification from the activity of a $\mathrm{Cl}^{-}$channel instead of a $2 \mathrm{Cl}^{-} / \mathrm{H}^{+}$exchanger. This would in turn impair the endosomal/lysosomal pathway of the proximal tubule (Novarino et al., 2010 ; Weinert et al., 2010). 
In Dent' diseases 1, no correlation between type of mutation and phenotype has been described (Mansour-Hendili et al., 2015). Patient harboring E211Q mutation has high LMWP (urinary $\beta-2$ microglobuline $37.5 \mathrm{mg} / \mathrm{L}$ ), hypercalciuria, nephrocalcinosis and normal renal function at 7.4 years old. Our patient harboring E211G mutation also has high LMWP (urinary $\alpha-1$ microglobuline $196 \mathrm{mg} / \mathrm{L}$ ), hypercalciuria without nephrocalcinosis but developed CKD at 5 years old.

Our data demonstrate that LMWP proteinuria observed in the patient harboring the E211G mutation cannot be explained by alterations in endocytosis due to defective endosomal acidification, but rather strongly suggest an involvement of intraluminal $\mathrm{Cl}^{-}$in this phenomenon (Smith \& Lippiat, 2010). Interestingly, the pivotal role of ClC-5 in controlling vesicular $\mathrm{Cl}^{-}$concentration for proper proximal tubule endocytosis is further semperted

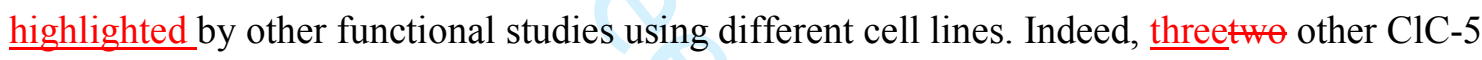

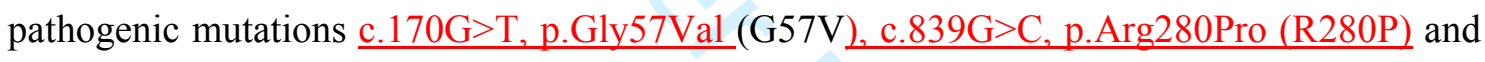
c.86 88dup, p.Asp29 Arg30insHis (30:insH) positioned at quite distance from the "gating glutamate" induced similar disturbances. Respectively in HEK-MSR cells and in immortalized proximal tubular epithelial cells from patients with Dent's $\underline{\text { Dent }}$ disease 1 expressing those three ClC-5 mutants, authors were not able to see any abnormal endosomal acidification (Gorvin et al., 2013; Smith et al., 2009). However, defective receptor-mediated endocytosis was also observed with the 30:insH mutation, whereas fluidphase endocytosis was unaffected. Several hypotheses have been proposed to explain the involvement of luminal $\mathrm{Cl}^{-}$in the endosomal pathway (Stauber \& Jentsch, 2013). Changes in $\mathrm{Cl}^{-}$concentration may for instance affect $\mathrm{Ca}^{2+}$ efflux from members of the two-pore channel (TPC) family that are target for the second messenger nicotinic acid adenine dinucleotide phosphate (NAADP) or the transient receptor potential mucolipin (TRPML) family. These channels play a significant role in fusion and trafficking of the endo-lysosomal network by 
promoting local $\mathrm{Ca}^{2+}$ release (Brailoiu \& Brailoiu, 2016 ; Grimm, Butz, Chen, Wahl-Schott, \& Biel, 2017). Alternatively, because these organelles are highly permeable to water, alterations in luminal $\mathrm{Cl}^{-}$concentration may influence their shape via an osmotic effect. These changes could prevent formation of tubular membranes that are required for the formation or the fusion of endosomes and lysosomes (Scott \& Gruenberg, 2011).

In this context, further experiments using a vector encoding a protein-based Clsensitive probe specifically targeted to early endosomes would be needed to measure the impact on endosomal chloride concentration of the mutations that do not impair endosomal acidification (G57V, 30:insH, R280P and E211G). Unfortunately, such probe is still yet-tobe-developped: intracellular chloride reporters have been described but none of them are able to specifically reach endosomal compartments (Arosio \& Ratto, 2014; Gensch, Untiet, Franzen, Kovermann, \& Fahlke, 2015 ; Sulis Sato et al., 2017). Theese experiments will be necessary to unravel the importance of chloride accumulation in early endosomes and to determine if a reduced endosomal chloride concentration could be the cellular defect shared by all CLCN5 pathogenic mutations. Further experiments will be needed to unravel the precise molecular mechanisms linking $\mathrm{Cl}^{-}$-accumulation in early endosomes of proximal tubule cells and endocytosis in Dent's disease 1.

In conclusion, it is possible that the physicochemical characteristics of amino acid changes could determine the mechanism involved in the physiopathology of mutations of the ClC-5 protein and on the consequences either on $\mathrm{Cl}^{-}$accumulation, and / or on endosomal acidification. Such phenomenon could contribute to the absence of correlation of genotypephenotype in Đent's $\underline{\text { Dent disease. }}$ 


\section{ACKNOWLEDGMENTS}

We thank Prof. Thomas J. Jentsch for kindly providing the HA-tagged ClC-5, Christophe Klein for excellent technical assistance in confocal microscopy, Gabrielle Planelles and Naziha Bakouh for support and help with oocytes. We also thank Marc Ambrosini and Yohan Legueux-Cajgfinger for their contributions during their graduate studies at Université Pierre et Marie Curie. This work was supported by the grant RAD16003DDA from the Fondation du Rein. Yohan Bignon holds a fellowship from the French Ministère de 1'Enseignement Supérieur et de la Recherche. 


\section{REFERENCES}

Accardi, A., \& Miller, C. (2004). Secondary active transport mediated by a prokaryotic homologue of ClC Cl- channels. Nature, 427(6977), 803-7.

Alekov, A. K. (2015). Mutations associated with Dent's disease affect gating and voltage dependence of the human anion/proton exchanger ClC-5. Front Physiol, 6, 159.

Alekov, Alexi K., \& Fahlke, C. (2009). Channel-like slippage modes in the human anion/proton exchanger ClC-4. The Journal of General Physiology, 133(5), 485-496. https://doi.org/10.1085/jgp.200810155

Arosio, D., \& Ratto, G. M. (2014). Twenty years of fluorescence imaging of intracellular chloride. Frontiers in Cellular Neuroscience, 8, 258. https://doi.org/10.3389/fncel.2014.00258

Brailoiu, G. C., \& Brailoiu, E. (2016). Modulation of Calcium Entry by the Endo-lysosomal System. Advances in Experimental Medicine and Biology, 898, 423-447. https://doi.org/10.1007/978-3-319-26974-0_18

Crocker, J. C., \& Grier, D. G. (1996). Methods of digital video microscopy for colloidal studies. J Colloid Interface, 179, 298-310.

D’Antonio, C., Molinski, S., Ahmadi, S., Huan, L. J., Wellhauser, L., \& Bear, C. E. (2013). Conformational defects underlie proteasomal degradation of Dent's disease-causing mutants of ClC-5. Biochem J, 452(3), 391-400.

Devuyst, O., Christie, P. T., Courtoy, P. J., Beauwens, R., \& Thakker, R. V. (1999). Intrarenal and subcellular distribution of the human chloride channel, CLC-5, reveals a pathophysiological basis for Dent's disease. Hum Mol Genet, 8(2), 247-57.

Devuyst, O., \& Luciani, A. (2015). Chloride transporters and receptor-mediated endocytosis in the renal proximal tubule. J Physiol, 593(18), 4151-64.

Dutzler, R., Campbell, E. B., Cadene, M., Chait, B. T., \& MacKinnon, R. (2002). X-ray structure of a $\mathrm{ClC}$ chloride channel at 3.0 A reveals the molecular basis of anion selectivity. Nature, 415(6869), 287-94.

Dutzler, R., Campbell, E. B., \& MacKinnon, R. (2003). Gating the selectivity filter in ClC chloride channels. Science, 300(5616), 108-12.

Feng, L., Campbell, E. B., Hsiung, Y., \& MacKinnon, R. (2010). Structure of a eukaryotic CLC transporter defines an intermediate state in the transport cycle. Science, 330(6004), 635-41.

Friedrich, T., Breiderhoff, T., \& Jentsch, T. J. (1999). Mutational analysis demonstrates that ClC-4 and ClC-5 directly mediate plasma membrane currents. J Biol Chem, 274(2), 896-902.

Gensch, T., Untiet, V., Franzen, A., Kovermann, P., \& Fahlke, C. (2015). Determination of Intracellular Chloride Concentrations by Fluorescence Lifetime Imaging. Dans Advanced Time-Correlated Single Photon Counting Applications (pp. 189-211). (S.1.) : Springer, Cham. https://doi.org/10.1007/978-3-319-14929-5_4

Gorvin, C. M., Wilmer, M. J., Piret, S. E., Harding, B., van den Heuvel, L. P., Wrong, O., ... Thakker, R. V. (2013). Receptor-mediated endocytosis and endosomal acidification is impaired in proximal tubule epithelial cells of Dent disease patients. Proc Natl Acad Sci US A, 110(17), 7014-9.

Graham, F. L., \& van der Eb, A. J. (1973). A new technique for the assay of infectivity of human adenovirus 5 DNA. Virology, 52(2), 456-467. 
Grand, T., L’Hoste, S., Mordasini, D., Defontaine, N., Keck, M., Pennaforte, T., ... Lourdel, S. (2011). Heterogeneity in the processing of CLCN5 mutants related to Dent disease. Hum Mutat, 32(4), 476-83.

Grand, T., Mordasini, D., L'Hoste, S., Pennaforte, T., Genete, M., Biyeyeme, M. J., ... Lourdel, S. (2009). Novel CLCN5 mutations in patients with Dent's disease result in altered ion currents or impaired exchanger processing. Kidney Int, 76(9), 999-1005.

Grieschat, M., \& Alekov, A. K. (2014). Multiple discrete transitions underlie voltagedependent activation in $\mathrm{CLC} \mathrm{Cl}(-) / \mathrm{H}(+)$ antiporters. Biophysical Journal, 107(6), L13-15. https://doi.org/10.1016/j.bpj.2014.07.063

Grimm, C., Butz, E., Chen, C.-C., Wahl-Schott, C., \& Biel, M. (2017). From mucolipidosis type IV to Ebola: TRPML and two-pore channels at the crossroads of endo-lysosomal trafficking and disease. Cell Calcium. https://doi.org/10.1016/j.ceca.2017.04.003

Gunther, W., Luchow, A., Cluzeaud, F., Vandewalle, A., \& Jentsch, T. J. (1998). ClC-5, the chloride channel mutated in Dent's disease, colocalizes with the proton pump in endocytotically active kidney cells. Proc Natl Acad Sci U S A, 95(14), 8075-80.

Gunther, W., Piwon, N., \& Jentsch, T. J. (2003). The ClC-5 chloride channel knock-out mouse - an animal model for Dent's disease. Pflugers Arch, 445(4), 456-62.

Hamill, O. P., Marty, A., Neher, E., Sakmann, B., \& Sigworth, F. J. (1981). Improved patchclamp techniques for high-resolution current recording from cells and cell-free membrane patches. Pflugers Archiv: European Journal of Physiology, 391(2), 85100.

Hoopes, R. R., Jr., Shrimpton, A. E., Knohl, S. J., Hueber, P., Hoppe, B., Matyus, J., ... Scheinman, S. J. (2005). Dent Disease with mutations in OCRL1. Am J Hum Genet, 76(2), 260-7.

Hryciw, D. H., Ekberg, J., Pollock, C. A., \& Poronnik, P. (2006). ClC-5: a chloride channel with multiple roles in renal tubular albumin uptake. Int $J$ Biochem Cell Biol, 38(7), 1036-42.

Hryciw, D. H., Jenkin, K. A., Simcocks, A. C., Grinfeld, E., McAinch, A. J., \& Poronnik, P. (2012). The interaction between megalin and ClC-5 is scaffolded by the $\mathrm{Na}^{+}-\mathrm{H}^{+}$ exchanger regulatory factor 2 (NHERF2) in proximal tubule cells. The International Journal of Biochemistry \& Cell Biology, 44(5), 815-823. https://doi.org/10.1016/j.biocel.2012.02.007

Hryciw, D. H., Kruger, W. A., Briffa, J. F., Slattery, C., Bolithon, A., Lee, A., \& Poronnik, P. (2012). Sgk-1 is a positive regulator of constitutive albumin uptake in renal proximal tubule cells. Cellular Physiology and Biochemistry: International Journal of Experimental Cellular Physiology, Biochemistry, and Pharmacology, 30(5), 12151226. https://doi.org/10.1159/000343313

Jentsch, T. J. (2015). Discovery of CLC transport proteins: cloning, structure, function and pathophysiology. The Journal of Physiology. https://doi.org/10.1113/jphysiol.2014.270043

Lloyd, S. E., Pearce, S. H., Gunther, W., Kawaguchi, H., Igarashi, T., Jentsch, T. J., \& Thakker, R. V. (1997). Idiopathic low molecular weight proteinuria associated with hypercalciuric nephrocalcinosis in Japanese children is due to mutations of the renal chloride channel (CLCN5). J Clin Invest, 99(5), 967-74.

Lourdel, S., Grand, T., Burgos, J., Gonzalez, W., Sepulveda, F. V., \& Teulon, J. (2012). ClC5 mutations associated with Dent's disease: a major role of the dimer interface. Pflugers Arch, 463(2), 247-56.

Ludwig, M., Doroszewicz, J., Seyberth, H. W., Bokenkamp, A., Balluch, B., Nuutinen, M., ... Waldegger, S. (2005). Functional evaluation of Dent's disease-causing mutations: 
implications for ClC-5 channel trafficking and internalization. Hum Genet, 117(2-3), 228-37.

Mahon, M. J. (2011). pHluorin2: an enhanced, ratiometric, $\mathrm{pH}$-sensitive green florescent protein. Advances in Bioscience and Biotechnology (Print), 2(3), 132-137. https://doi.org/10.4236/abb.2011.23021

Mansour-Hendili, L., Blanchard, A., Le Pottier, N., Roncelin, I., Lourdel, S., Treard, C., ... Vargas-Poussou, R. (2015). Mutation Update of the CLCN5 Gene Responsible for Dent Disease 1. Hum Mutat, 36(8), 743-52.

Matsuda, J. J., Filali, M. S., Collins, M. M., Volk, K. A., \& Lamb, F. S. (2010). The ClC-3 $\mathrm{Cl}-\mathrm{H}+$ antiporter becomes uncoupled at low extracellular pH. J Biol Chem, 285(4), 2569-79.

Miesenböck, G., De Angelis, D. A., \& Rothman, J. E. (1998). Visualizing secretion and synaptic transmission with $\mathrm{pH}$-sensitive green fluorescent proteins. Nature, 394(6689), 192-195. https://doi.org/10.1038/28190

Neagoe, I., Stauber, T., Fidzinski, P., Bergsdorf, E. Y., \& Jentsch, T. J. (2010). The late endosomal ClC-6 mediates proton/chloride countertransport in heterologous plasma membrane expression. J Biol Chem, 285(28), 21689-97.

Novarino, G., Weinert, S., Rickheit, G., \& Jentsch, T. J. (2010). Endosomal chloride-proton exchange rather than chloride conductance is crucial for renal endocytosis. Science, 328(5984), 1398-401.

Picollo, A., \& Pusch, M. (2005). Chloride/proton antiporter activity of mammalian CLC proteins ClC-4 and ClC-5. Nature, 436(7049), 420-3.

Piwon, N., Gunther, W., Schwake, M., Bosl, M. R., \& Jentsch, T. J. (2000). ClC-5 Cl- channel disruption impairs endocytosis in a mouse model for Dent's disease. Nature, 408(6810), 369-73.

Rasband, W. S. (n.d.). ImageJ US Natl Inst Health. https://imagej.nih.gov/ij/

Reed, A. A., Loh, N. Y., Terryn, S., Lippiat, J. D., Partridge, C., Galvanovskis, J., ... Thakker, R. V. (2010). CLC-5 and KIF3B interact to facilitate CLC-5 plasma membrane expression, endocytosis, and microtubular transport: relevance to pathophysiology of Dent's disease. Am J Physiol Renal Physiol, 298(2), F365-80.

Sakamoto, H., Sado, Y., Naito, I., Kwon, T. H., Inoue, S., Endo, K., ... Marumo, F. (1999). Cellular and subcellular immunolocalization of $\mathrm{ClC}-5$ channel in mouse kidney: colocalization with H+-ATPase. Am J Physiol, $277(6$ Pt 2), F957-65.

Satoh, N., Yamada, H., Yamazaki, O., Suzuki, M., Nakamura, M., Suzuki, A., ... Horita, S. (2016). A pure chloride channel mutant of CLC-5 causes Dent's disease via insufficient V-ATPase activation. Pflugers Archiv: European Journal of Physiology, 468(7), 1183-1196. https://doi.org/10.1007/s00424-016-1808-7

Scheel, O., Zdebik, A. A., Lourdel, S., \& Jentsch, T. J. (2005). Voltage-dependent electrogenic chloride/proton exchange by endosomal CLC proteins. Nature, 436(7049), 424-7.

Scott, C. C., \& Gruenberg, J. (2011). Ion flux and the function of endosomes and lysosomes: $\mathrm{pH}$ is just the start: the flux of ions across endosomal membranes influences endosome function not only through regulation of the luminal pH. BioEssays: News and Reviews in Molecular, Cellular and Developmental Biology, 33(2), 103-110. https://doi.org/10.1002/bies.201000108

Smith, A. J., \& Lippiat, J. D. (2010). Direct endosomal acidification by the outwardly rectifying CLC-5 $\mathrm{Cl}(-) / \mathrm{H}(+)$ exchanger. The Journal of Physiology, 588(Pt 12), 20332045. https://doi.org/10.1113/jphysiol.2010.188540 
Smith, A. J., Reed, A. A., Loh, N. Y., Thakker, R. V., \& Lippiat, J. D. (2009). Characterization of Dent's disease mutations of CLC-5 reveals a correlation between functional and cell biological consequences and protein structure. Am J Physiol Renal Physiol, 296(2), F390-7.

Stauber, T., \& Jentsch, T. J. (2013). Chloride in vesicular trafficking and function. Annual Review of Physiology, 75, 453-477. https://doi.org/10.1146/annurev-physiol-030212183702

Steinmeyer, K., Schwappach, B., Bens, M., Vandewalle, A., \& Jentsch, T. J. (1995). Cloning and functional expression of rat CLC-5, a chloride channel related to kidney disease. $J$ Biol Chem, 270(52), 31172-7.

Sulis Sato, S., Artoni, P., Landi, S., Cozzolino, O., Parra, R., Pracucci, E., ... Ratto, G. M. (2017). Simultaneous two-photon imaging of intracellular chloride concentration and $\mathrm{pH}$ in mouse pyramidal neurons in vivo. Proceedings of the National Academy of Sciences of the United States of America, 114(41), E8770-E8779. https://doi.org/10.1073/pnas.1702861114

Suzuki, T., Rai, T., Hayama, A., Sohara, E., Suda, S., Itoh, T., ... Uchida, S. (2006). Intracellular localization of $\mathrm{ClC}$ chloride channels and their ability to form heterooligomers. J Cell Physiol, 206(3), 792-8.

Tang, X., Brown, M. R., Cogal, A. G., Gauvin, D., Harris, P. C., Lieske, J. C., ... Chang, M.H. (2016). Functional and transport analyses of CLCN5 genetic changes identified in Dent disease patients. Physiological Reports, 4(8). https://doi.org/10.14814/phy2.12776

Wang, Y., Cai, H., Cebotaru, L., Hryciw, D. H., Weinman, E. J., Donowitz, M., ... Guggino, W. B. (2005). ClC-5: role in endocytosis in the proximal tubule. Am J Physiol Renal Physiol, 289(4), F850-62.

Weinert, S., Jabs, S., Supanchart, C., Schweizer, M., Gimber, N., Richter, M., ... Jentsch, T. J. (2010). Lysosomal pathology and osteopetrosis upon loss of H+-driven lysosomal Cl- accumulation. Science (New York, N.Y.), 328(5984), 1401-1403. https://doi.org/10.1126/science. 1188072 


\section{FIGURE LEGENDS}

Figure 1. Functional characterization of WT ClC-5 and E211G mutant in X. laevis oocytes. A: Representative voltage-clamp recordings obtained from oocytes expressing WT and E211G ClC-5, and from noninjected oocytes in ND96 solution. B: Steady-state currentvoltage relationships obtained under the same conditions as described in A. Each data point represents the mean \pm SEM for at least 8 oocytes from three different batches (WT, $n=19$; E211G, $n=17$; NI, $n=8)$. C: Currents/cell surface expression relationship for WT ClC-5 and E211G mutant in $X$. laevis oocytes. Currents at $+100 \mathrm{mV}$ are from the same data as in panel A. For cell surface expression, the values (measured in RLU: Relative Light Units) were normalized to those of WT ClC-5 in the same batch of oocytes. Each column represents the mean \pm SEM for at least 8 oocytes for current recordings, and at least 40 oocytes from three different batches of oocytes for the surface expression. D: Extracellular $\mathrm{pH}$ dependence obtained from $X$. laevis expressing WT and E211G ClC-5 in ND96 solution at pH 5.5, 6.5, 7.0, 7.4 and 8.5. Currents at $+100 \mathrm{mV}$ were normalized for individual oocytes in the same batch of oocytes to the current at $+100 \mathrm{mV}$ in ND96 solution at $\mathrm{pH}$ 7.4. WT, oocytes injected with wild-type ClC-5; NI, noninjected oocytes. ${ }^{*}, P<0.001$ is the difference between WT or E211G ClC-5 versus NI. \#, $P<0.001$ is the difference between NI or E211G ClC-5 versus WT ClC-5. WT, oocytes injected with wild-type ClC-5; NI, noninjected oocytes.

Figure 2. Subcellular localization of WT ClC-5 and E211G mutant in HEK293T transfected cells. ClC-5 expression was detected by green fluorescence. Plasma membrane and early endosomes were stained by biotin and Early Endosome Antigen 1 marker (EEA1), and were detected by red fluorescence. The yellow fluorescence indicates the overlap of $\mathrm{ClC}-5$ and the organelles. Scale bars, $8 \mu \mathrm{m}$. WT, wild-type. 
Figure 3. Cell surface biotinylation and western-blot analysis of WT ClC-5 and E211G mutant in HEK293T transfected cells. A: Results are shown as western blot analysis of the surface biotinylated protein fraction $(\mathrm{S})$ or total cell lysates $(\mathrm{T})$. The right panel shows densitometric analysis of total and cell surface ClC-5 as normalized expression to WT ClC-5. Each column represents the mean \pm SEM from four experiments. Mock refers to HEK293T cells transfected without the expression vector; WT and E211G refer to HEK293T cells transfected with WT or mutant ClC-5. B: Total cell lysates were isolated from HEK293T cells $48 \mathrm{~h}$ after transfection with ClC-5. Actin was used as the loading marker of the samples. The right panel shows semi-quantification of the blots by densitometry analysis. Protein expression was normalized to those of WT ClC-5. Each column represents the mean \pm SEM from three experiments.

Figure 4. Measurement of proton flux of WT ClC-5 and E211G mutant in HEK293T transfected cells. A: Representative whole-cell recording and B: current-voltage relationship obtained from HEK293T cells expressing E211G $(n=7)$ or E211Q C1C-5 $(n=10)$. Data are presented as mean \pm SEM. C: Representative intracellular $\mathrm{pH}$ changes recorded at different voltages in a HEK293T transfected cells expressing WT or E211G ClC-5 using BCECF fluorimetry. Lines represent linear fits to the data and were used to provide the rates of intracellular $\mathrm{pH}$ changes $\Delta p H / \Delta t$. The insets depict the macroscopic whole cell currents measured in the same cells. D: Averaged rates of intracellular $\mathrm{pH}$ changes as function of clamp voltage. The red line represents the scaled current-voltage relationship of WT ClC-5. Each data point represents the mean \pm SEM from 5 different cells. 
Figure 5. Effects of WT and E211G ClC-5 on endosomal acidification in HEK293T transfected cells. A: Representative confocal images as used for determining intracellular $\mathrm{pH}$. The large image represents the overlay of mCherry $\mathrm{ClC}-5$ (red fluorescence) and synaptopHluorin2 (green fluorescence). Scale bars, $10 \mu \mathrm{m}$. B: Illustration of the particle identification used to select individual vesicular regions in the red channel (ClC-5 containing endosomes) and used to measure the fluorescence intensities in both pHluorin2 channels. The identified particles are overlaid as circles on the red channel of the cells depicted in A. C: Endosomal $\mathrm{pH}$ measured from cells transfected with pHluorin2 (Mock, $n=55$ ) or with ClC-5 (WT, $n=30 ; \mathrm{E} 211 \mathrm{G}, n=41$ ). 


\begin{tabular}{|c|c|c|c|c|c|c|}
\hline \multirow[b]{2}{*}{ Age (years) } & \multicolumn{5}{|c|}{ E211G Patient } & \multirow{2}{*}{$\begin{array}{c}\text { Mother } \\
28 \\
\end{array}$} \\
\hline & 1.5 & 1.9 & 2.4 & 4.3 & 5.75 & \\
\hline Weight & - & 10.3 & 11.3 & 13.4 & 13.5 & - \\
\hline Height & - & 82.4 & 86.5 & 100 & 110 & - \\
\hline \multicolumn{7}{|l|}{ Plasma concentrations } \\
\hline Sodium (133-146 mmol/L) & 124 & 136 & 137 & 132 & 135 & 138 \\
\hline Potassium $(3,5-5 \mathrm{mmol} / \mathrm{L})$ & 2.0 & 3.3 & 3.2 & 2.7 & 3.0 & 3.9 \\
\hline Chloride (90-117 mmol/L) & 82 & 99 & 97 & 82 & 88 & 106 \\
\hline $\mathrm{CO} 2 \mathrm{t}(18-25 \mathrm{mmol} / \mathrm{L})$ & 22 & 27 & 26 & 25 & 23 & - \\
\hline Calcium $(2.2-2.6 \mathrm{mmol} / \mathrm{L})$ & - & 2.48 & 2.61 & 2.39 & 2.41 & - \\
\hline $\begin{array}{r}\text { Phosphate }(1-5 \text { yr } 1.45-2.10 ; \\
\text { Adult } 0.85-1.50 \mathrm{mmol} / \mathrm{L})\end{array}$ & 0.9 & 1.58 & 1.62 & - & - & - \\
\hline Magnesium $(0.75-1 \mathrm{mmol} / \mathrm{L})$ & - & 0.86 & 0.77 & - & - & - \\
\hline Proteins (1-15 yr: 56-75; Adult: $64-83$ g/L) & 76 & 70 & 76 & 73 & 76 & 77 \\
\hline Albumin (1-15 yr: $30-42 ; \quad$ Adult: $35-50 \mathrm{~g} / \mathrm{L})$ & - & 46 & - & - & - & - \\
\hline Urea (1-15 yr:1.6-6.5; Adult: $2.5-87.5 \mathrm{mmol} / \mathrm{L})$ & 9.6 & 5.9 & 8.3 & - & - & 4.6 \\
\hline Creatinine $* *$ & 46 & 34 & 35 & 61 & 65 & 59 \\
\hline $\begin{array}{l}\text { Uric Acid (1-15 yr: } 120-320 \\
\text { Adult: } 150-400 \mathrm{mmol} / \mathrm{L})\end{array}$ & - & 181 & 173 & - & - & 271 \\
\hline Glucose $(4.1-5.9 \mathrm{mmol} / \mathrm{L})$ & - & 4.9 & 7.8 & - & 4.1 & 5.2 \\
\hline PTH (10-46 ng/L) & - & 32 & 24 & - & - & - \\
\hline 25 Vitamin D $(30-80 \mu \mathrm{g} / \mathrm{L})$ & - & 22 & - & - & - & - \\
\hline 1-25 Vitamin D (10-110ng/L) & - & 64 & - & - & - & - \\
\hline $\operatorname{Renin}(8-180 \mathrm{UI} / \mathrm{L})$ & - & 470 & - & - & - & $19.3^{\mathrm{a}}$ \\
\hline Aldosterone (70-800 pg/ml) & - & 240 & - & - & - & - \\
\hline Urine & & & & & & - \\
\hline FE Sodium $(<1 \%)$ & - & 0.26 & 0.37 & - & - & 0.78 \\
\hline FE Potassium (9-23\%) & - & 25 & 23 & - & - & 13.5 \\
\hline FE Uric acid (children: $15-22 \%$; females $10-14 \%$ ) & - & 18.1 & 14.9 & - & - & 7.4 \\
\hline FE Magnesium (1.5-3.5\%) & - & 5.9 & 5.2 & - & - & - \\
\hline $\operatorname{TRP}(\%)$ & - & 89.3 & 86.2 & - & - & - \\
\hline Calcium/creatinine $\left(\mathrm{mmol} / \mathrm{mmol}^{*}\right)$ & - & 1.65 & 1.32 & - & - & 0.44 \\
\hline Osmolality & - & 309 & 242 & - & - & 725 \\
\hline Aminoacids/creatinine $(\mu \mathrm{mol} / \mathrm{mmol})$ & - & 2267 & - & - & - & 725 \\
\hline Glucose $(0.3-1.1 \mathrm{mmol} / \mathrm{L})$ & - & $<0.3$ & $<0.3$ & - & - & $<0.3$ \\
\hline Protein $\mathrm{g} / \mathrm{L}$ & - & 1.2 & 0.98 & - & - & 0.08 \\
\hline Albumin $(<3 \mathrm{mg} / \mathrm{L})$ & - & 210 & 195 & - & - & $<6$ \\
\hline Alpha-1-microglobuline (mg/L) & - & 196 & - & - & - & $<4$ \\
\hline
\end{tabular}

Table 1. Clinical characteristics of the patient with Dent's disease 1 carrying the c.632A $>\mathrm{G}$, p.Glu211Gly (E211G) mutation.

*Reference values (CI 95\%) for $\mathrm{U} \mathrm{Ca} /$ creatinine ratio $(\mathrm{mM} / \mathrm{mM}): 1-2 \mathrm{yr}, 0.07-1.50 ; 2-3 \mathrm{yr}$, $0.06-1.40 ; 3-5 \mathrm{yr}, 0.05-1.10 ; 5-7 \mathrm{yr}, 0.04-0.80 ; 7-18 \mathrm{yr}, 0.04-0.70 ; 18-70 \mathrm{yr}, 0.04-0.70$. **Reference values for creatinine ( $\mu \mathrm{mol} / \mathrm{L}) ; 1-3$ yr 21-36; 3-5 yr: 27-42; 5-7 yr: 28-52; Adult Woman: $44-80^{\mathrm{a}}$ plasma renin concentration (normal range for adult: $10-50 \mathrm{mIU} / \mathrm{L}$ ). 


\begin{tabular}{|c|c|c|c|c|c|c|}
\hline \multirow[b]{2}{*}{ Age (years) } & \multicolumn{5}{|c|}{ E211G Patient } & \multirow{2}{*}{$\begin{array}{l}\text { Mother } \\
28\end{array}$} \\
\hline & 1.5 & 1.9 & 2.4 & 4.3 & 5.75 & \\
\hline Weight & - & 10.3 & 11.3 & 13.4 & 13.5 & - \\
\hline Height & - & 82.4 & 86.5 & 100 & 110 & - \\
\hline \multicolumn{7}{|l|}{ Plasma concentrations } \\
\hline Sodium (133-146 mmol/L) & 124 & 136 & 137 & 132 & 135 & 138 \\
\hline Potassium $(3,5-5$ mmol/L) & 2.0 & 3.3 & 3.2 & 2.7 & 3.0 & 3.9 \\
\hline Chloride (90-117 mmol/L) & 82 & 99 & 97 & 82 & 88 & 106 \\
\hline $\mathrm{CO} 2 \mathrm{t}(18-25 \mathrm{mmol} / \mathrm{L})$ & 22 & 27 & 26 & 25 & 23 & - \\
\hline Calcium $(2.2-2.6 \mathrm{mmol} / \mathrm{L})$ & - & 2.48 & 2.61 & 2.39 & 2.41 & - \\
\hline $\begin{array}{l}\text { Phosphate (1-5 yr 1.45-2.10; } \\
\text { Adult } 0.85-1.50 \mathrm{mmol} / \mathrm{L})\end{array}$ & 0.9 & 1.58 & 1.62 & - & - & - \\
\hline Magnesium $(0.75-1 \mathrm{mmol} / \mathrm{L})$ & - & 0.86 & 0.77 & - & - & - \\
\hline Proteins (1-15 yr: 56-75; Adult: $64-83 \mathrm{~g} / \mathrm{L})$ & 76 & 70 & 76 & 73 & 76 & 77 \\
\hline Albumin (1-15 yr: $30-42 ; \quad$ Adult: $35-50 \mathrm{~g} / \mathrm{L})$ & - & 46 & - & - & - & - \\
\hline Urea (1-15 yr:1.6-6.5; Adult: $2.5-87.5 \mathrm{mmol} / \mathrm{L}$ ) & 9.6 & 5.9 & 8.3 & - & - & 4.6 \\
\hline Creatinine $* *$ & 46 & 34 & 35 & 61 & 65 & 59 \\
\hline $\begin{array}{l}\text { Uric Acid (1-15 yr: } 120-320 \\
\text { Adult: } 150-400 \quad \mathrm{mmol} / \mathrm{L})\end{array}$ & - & 181 & 173 & - & - & 271 \\
\hline Glucose $(4.1-5.9 \mathrm{mmol} / \mathrm{L})$ & - & 4.9 & 7.8 & - & 4.1 & 5.2 \\
\hline PTH $(10-46$ ng/L) & - & 32 & 24 & - & - & - \\
\hline 25 Vitamin D $(30-80 \mu \mathrm{g} / \mathrm{L})$ & - & 22 & - & - & - & - \\
\hline 1-25 Vitamin D (10-110ng/L) & - & 64 & - & - & - & - \\
\hline $\operatorname{Renin}(8-180 \mathrm{UI} / \mathrm{L})$ & - & 470 & - & - & - & $19.3^{\mathrm{a}}$ \\
\hline Aldosterone $(70-800 \mathrm{pg} / \mathrm{ml})$ & - & 240 & - & - & - & - \\
\hline Urine & & 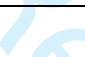 & & & & - \\
\hline FE Sodium $(<1 \%)$ & - & 0.26 & 0.37 & - & - & 0.78 \\
\hline FE Potassium $(9-23 \%)$ & - & 25 & 23 & - & - & 13.5 \\
\hline FE Uric acid (children: $15-22 \%$; females $10-14 \%$ ) & - & 18.1 & 14.9 & - & - & 7.4 \\
\hline FE Magnesium $(1.5-3.5 \%)$ & - & 5.9 & 5.2 & - & - & - \\
\hline TRP $(\%)$ & - & 89.3 & 86.2 & - & - & - \\
\hline Calcium/creatinine $\left(\mathrm{mmol} / \mathrm{mmol}^{*}\right)$ & - & 1.65 & 1.32 & - & - & 0.44 \\
\hline Osmolality & - & 309 & 242 & - & - & 725 \\
\hline Aminoacids/creatinine $(\mu \mathrm{mol} / \mathrm{mmol})$ & - & 2267 & - & - & - & 725 \\
\hline Glucose $(0.3-1.1 \mathrm{mmol} / \mathrm{L})$ & - & $<0.3$ & $<0.3$ & - & - & $<0.3$ \\
\hline Protein $g / L$ & - & 1.2 & 0.98 & - & - & 0.08 \\
\hline Albumin $(<3 \mathrm{mg} / \mathrm{L})$ & - & 210 & 195 & - & - & $<6$ \\
\hline Alpha-1-microglobuline (mg/L) & - & 196 & - & - & - & $<4$ \\
\hline
\end{tabular}

Table 1. Clinical characteristics of the patient with Dent's disease 1 carrying the $\underline{\text { c. } 632 \mathrm{~A}>\mathrm{G} \text {, }}$ p.Glu211Gly (E211G) E211G-mutation.

*Reference values (CI 95\%) for $\mathrm{U} \mathrm{Ca} /$ creatinine ratio $(\mathrm{mM} / \mathrm{mM})$ : $1-2 \mathrm{yr}, 0.07-1.50 ; 2-3 \mathrm{yr}$, $0.06-1.40 ; 3-5 \mathrm{yr}, 0.05-1.10 ; 5-7 \mathrm{yr}, 0.04-0.80 ; 7-18 \mathrm{yr}, 0.04-0.70 ; 18-70 \mathrm{yr}, 0.04-0.70$. **Reference values for creatinine $(\mu \mathrm{mol} / \mathrm{L}) ; 1-3$ yr 21-36; 3-5 yr: 27-42; 5-7 yr: 28-52; Adult Woman: $44-80^{\mathrm{a}}$ plasma renin concentration (normal range for adult: $10-50 \mathrm{mIU} / \mathrm{L}$ ). 
A

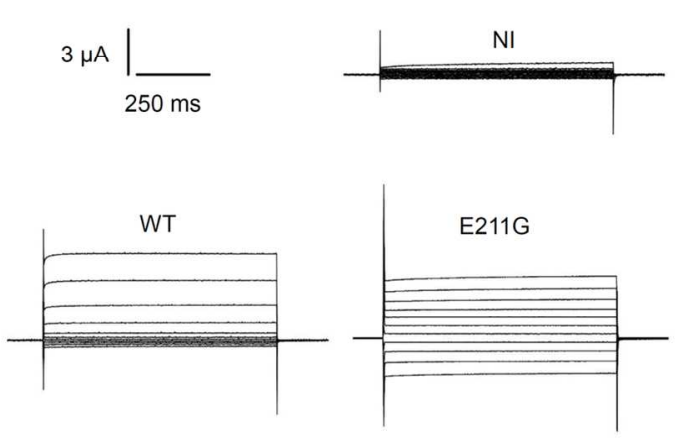

C

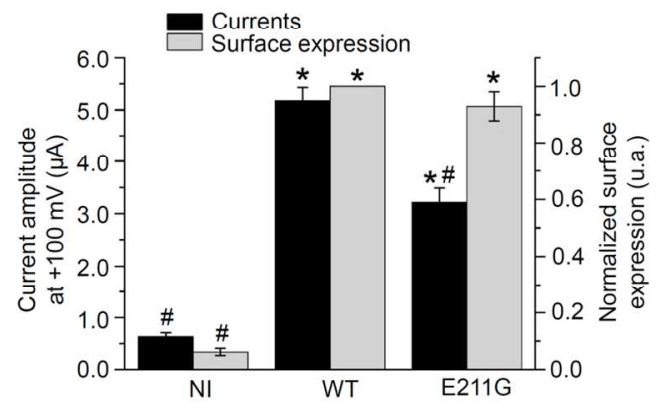

B

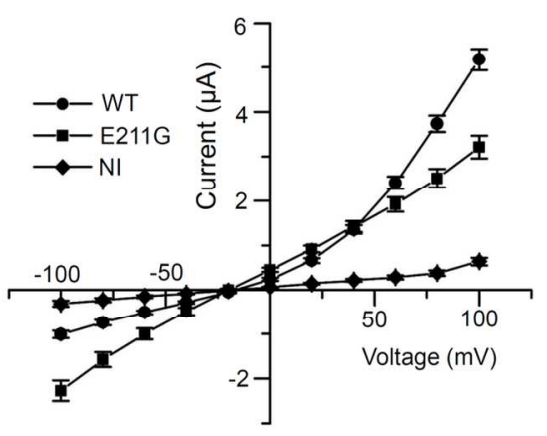

D

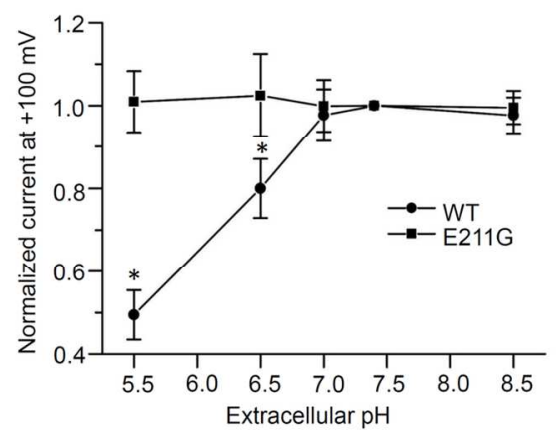

Figure 1

Figure 1

$135 \times 120 \mathrm{~mm}(300 \times 300$ DPI $)$

John Wiley \& Sons, Inc. 

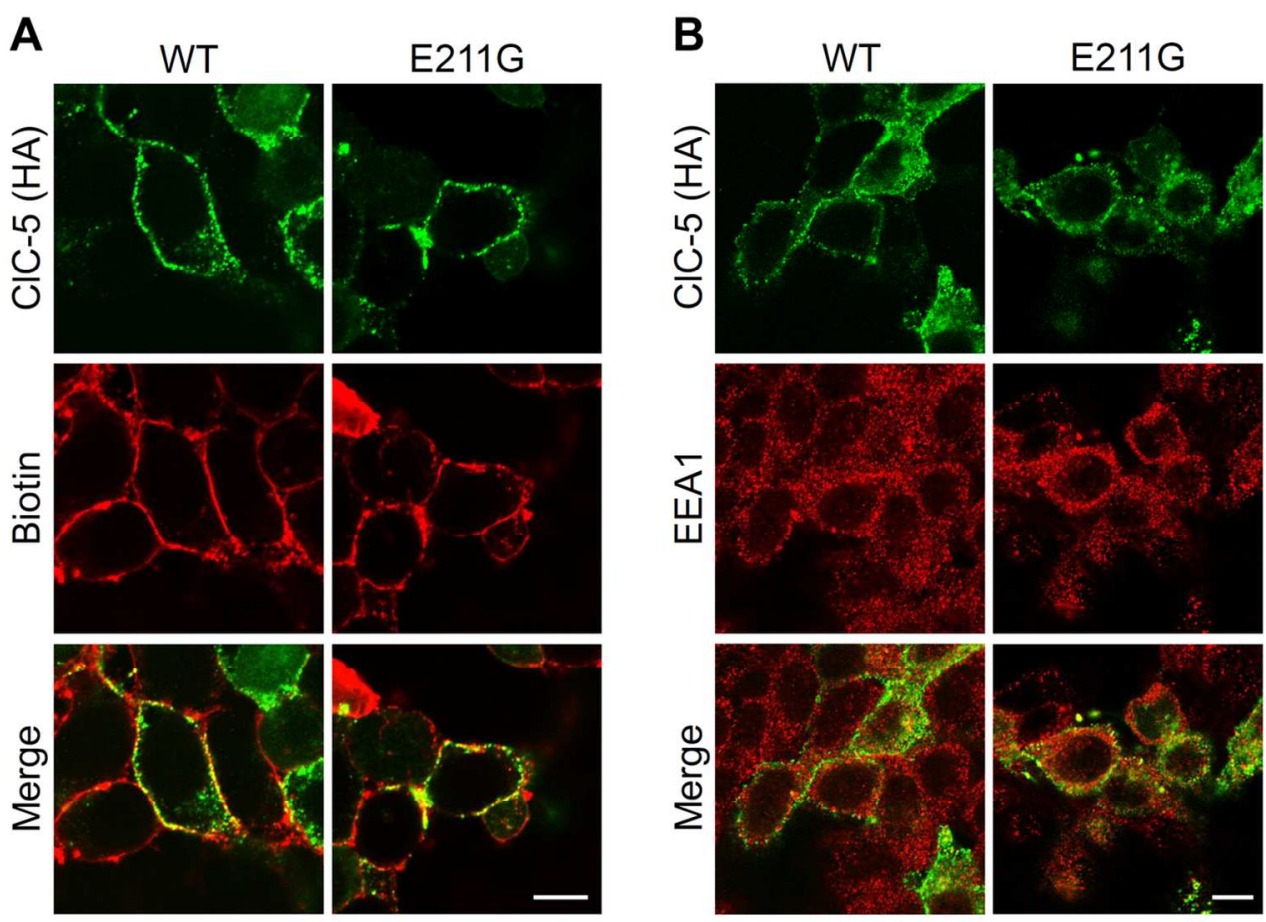

\section{Figure 2}

Figure 2

$121 \times 111 \mathrm{~mm}(300 \times 300$ DPI $)$

John Wiley \& Sons, Inc. 

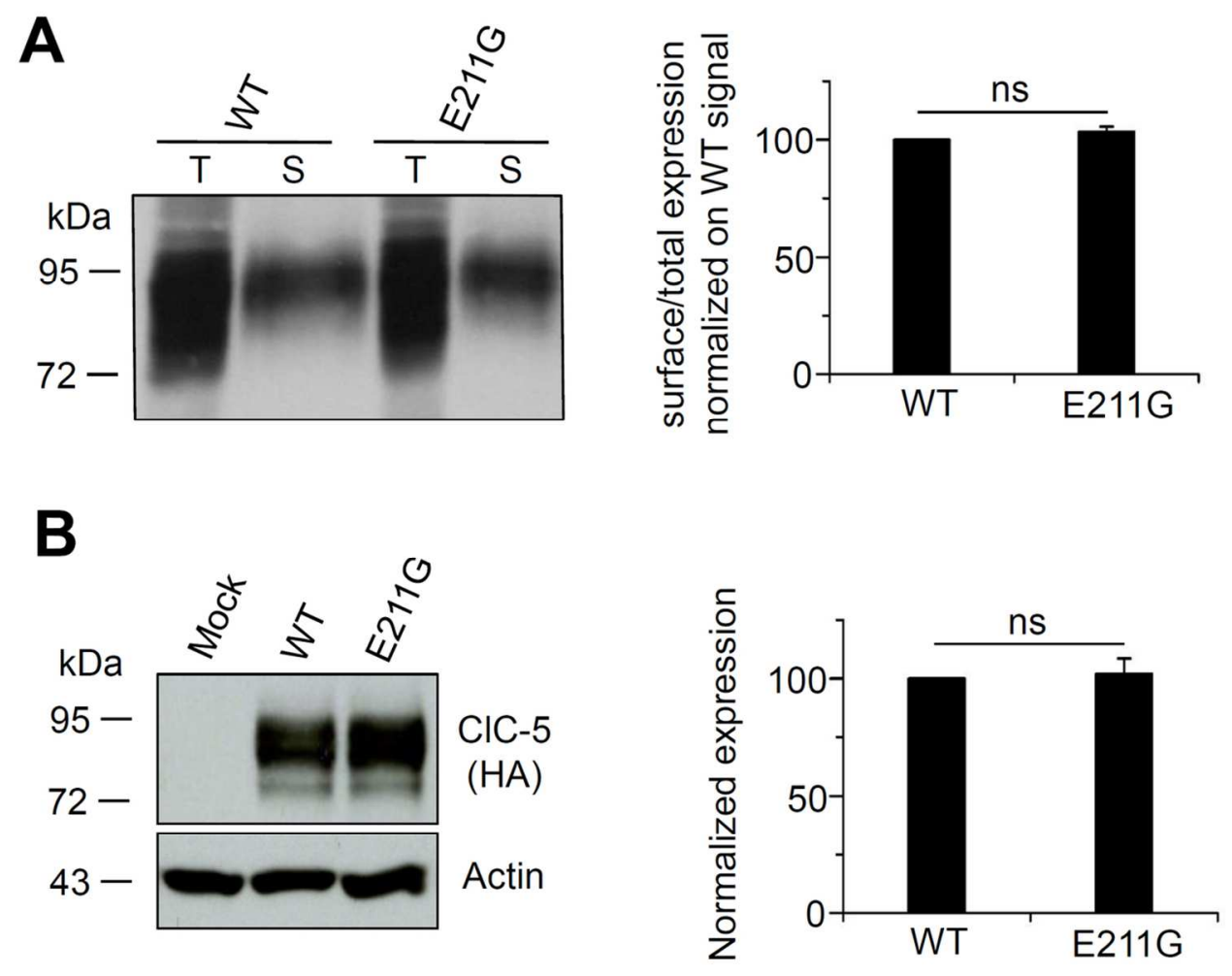

\section{Figure 3}

Figure 3

$111 \times 137 \mathrm{~mm}(300 \times 300$ DPI)

John Wiley \& Sons, Inc. 
A
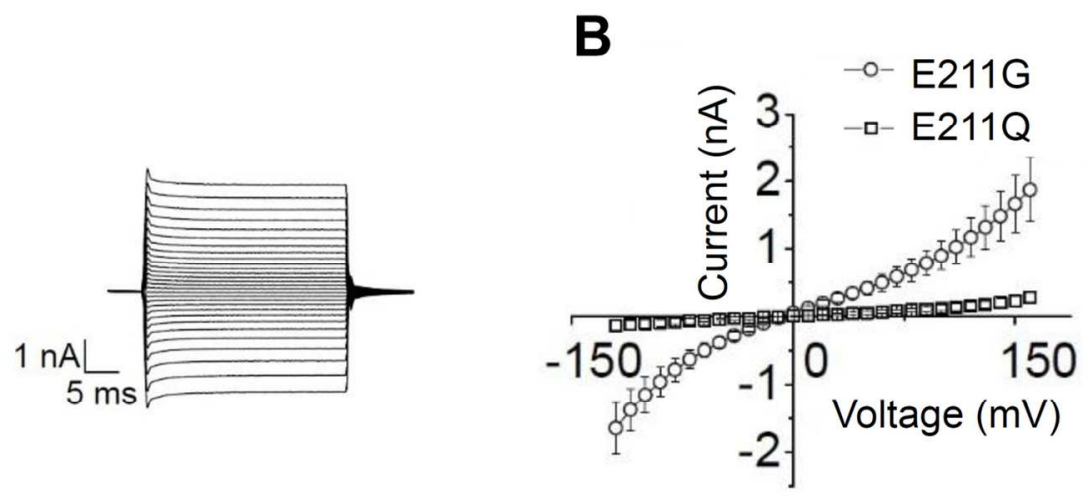

C

D
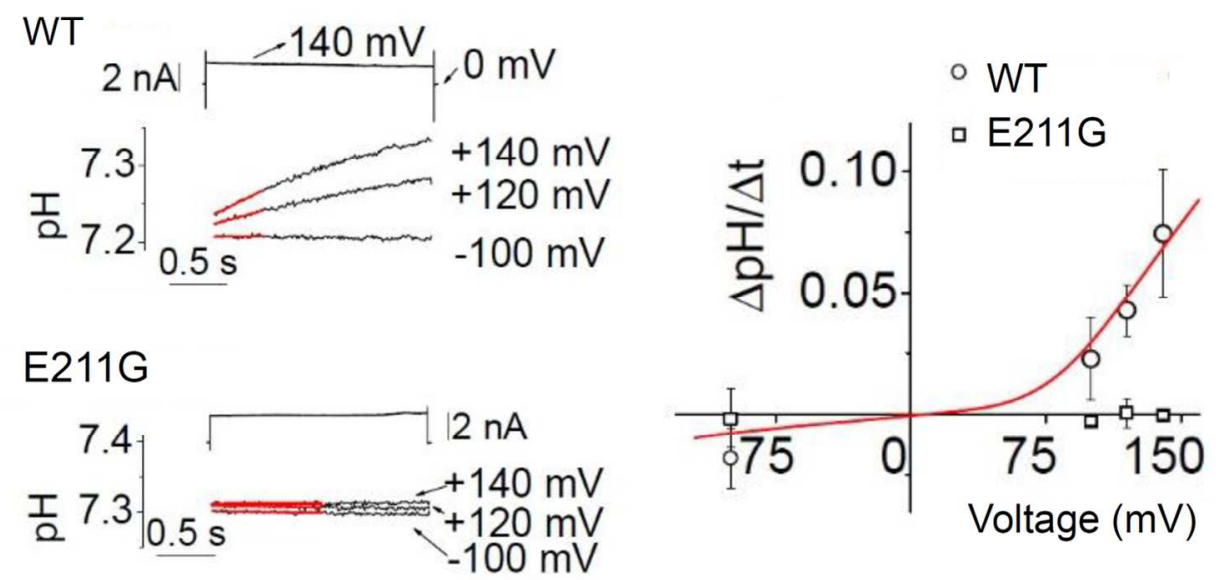

Figure 4

Figure 4

$126 \times 147 \mathrm{~mm}(300 \times 300$ DPI $)$

John Wiley \& Sons, Inc. 
A

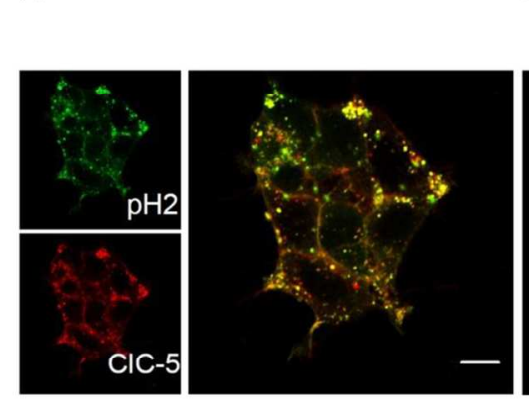

B

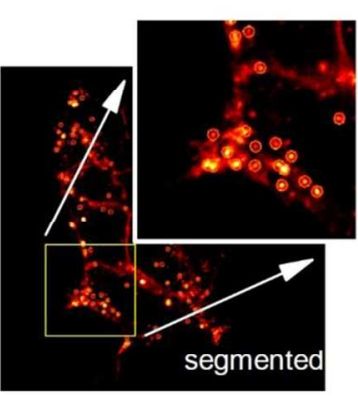

C

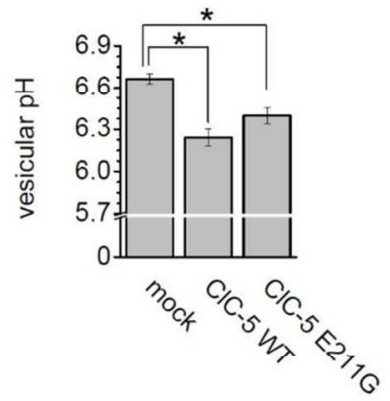

Figure 5

Figure 5

$113 \times 69 \mathrm{~mm}(300 \times 300$ DPI $)$

John Wiley \& Sons, Inc. 